Prepared in cooperation with New Jersey Department of Environmental Protection

\title{
Quality Assurance/Quality Control Procedure for New Jersey's Water-Use Data for the New Jersey Water Transfer Data System (NJWaTr)
}

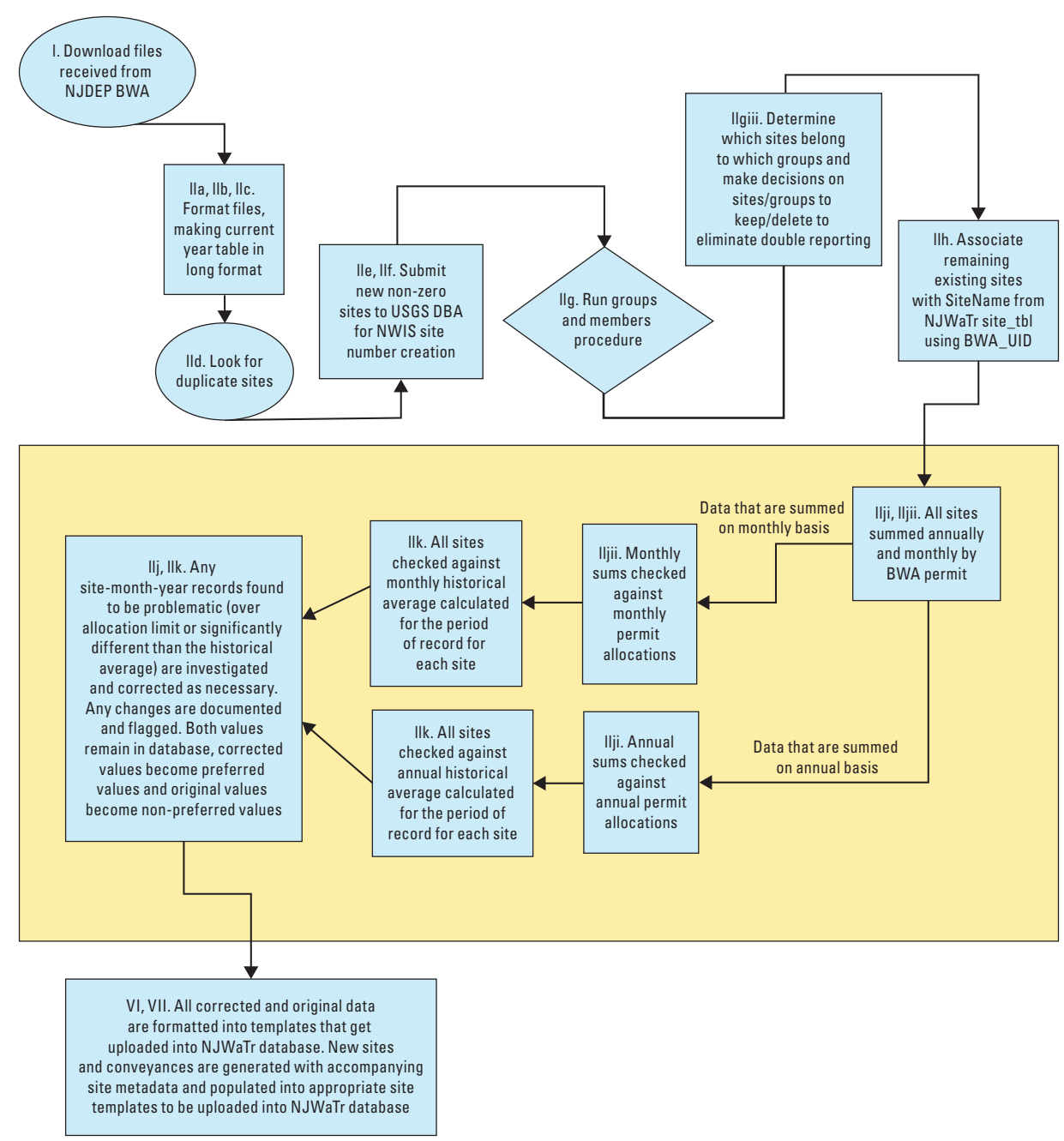

Open-File Report 2020-1085

U.S. Department of the Interior

U.S. Geological Survey 
Cover: Figure 1 in the report. 


\section{Quality Assurance/Quality Control Procedure for New Jersey's Water-Use Data for the New Jersey Water Transfer Data System (NJWaTr)}

By Jennifer L. Shourds

Prepared in cooperation with New Jersey Department of Environmental

Protection

Open-File Report 2020-1085 


\title{
U.S. Department of the Interior \\ DAVID BERNHARDT, Secretary
}

\author{
U.S. Geological Survey \\ James F. Reilly II, Director
}

U.S. Geological Survey, Reston, Virginia: 2020

For more information on the USGS - the Federal source for science about the Earth, its natural and living resources, natural hazards, and the environment—visit https://www.usgs.gov or call 1-888-ASK-USGS.

For an overview of USGS information products, including maps, imagery, and publications, visit https://store.usgs.gov/.

Any use of trade, firm, or product names is for descriptive purposes only and does not imply endorsement by the U.S. Government.

Although this information product, for the most part, is in the public domain, it also may contain copyrighted materials as noted in the text. Permission to reproduce copyrighted items must be secured from the copyright owner.

Suggested citation:

Shourds, J.L., 2020, Quality assurance/quality control procedure for New Jersey's water-use data for the New Jersey Water Transfer Data System (NJWaTr): U.S. Geological Survey Open-File Report 2020-1085, 26 p., https://doi.org/ 10.3133/ofr20201085.

ISSN 2331-1258 (online) 


\section{Preface}

The U.S. Geological Survey (USGS) has been involved in a cooperative project with the New Jersey Department of Environmental Protection (NJDEP) relating to the New Jersey Water Transfer Data System since 2004. The quality assurance/quality control procedure described in this document is executed on data received from the NJDEP Bureau of Water Allocation, and the data are therefore owned by the State of New Jersey. The USGS assumes no responsibility for the long-term preservation and accessibility of these data under Open Data guidelines that pertain to U.S. Government data products. 


\section{Acknowledgments}

The author gratefully acknowledges the many contributions and cooperation of Steve Domber, lan Snook, and Kent Barr of the New Jersey Department of Environmental Protection Geological and Water Survey. Thanks also go to Mike Bleicher, Carol Olynyk, and Yvens Dessalines of the New Jersey Department of Environmental Protection Bureau of Water Allocation for providing the data. The author thanks Martha Watt and Cheryl Dieter of the U.S. Geological Survey (USGS) for their extensive colleague reviews; their comments and suggestions were very helpful in revising this report. The author also appreciates the assistance and suggestions of Jon Janowicz (USGS) in the early draft stages of this report. Credit and gratitude are given to Mary Chepiga (USGS) for her creation of, and contributions to, the allocation limit tool. The author would like to acknowledge and thank Steve Tessler (USGS) for his contributions to the design and structure of the New Jersey Water Transfer System Database \& Tools and Don Rice (USGS) for his help with the wastewater data procedure. 


\section{Contents}

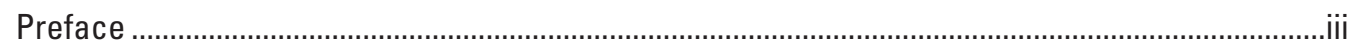

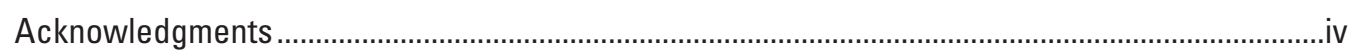

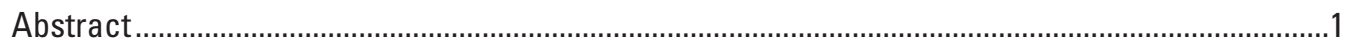

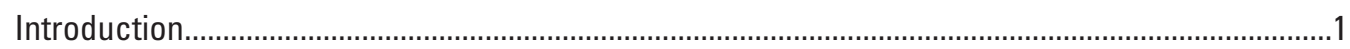

Quality Assurance/Quality Control Procedure For New Jersey's Water-Use Data...........................2

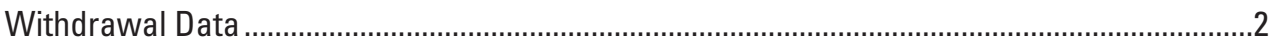

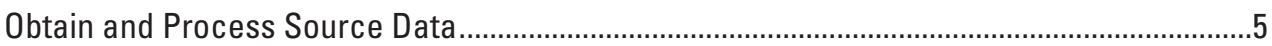

New Site Identification Creation and Vetting for Duplicates ....................................................6

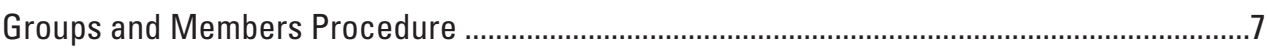

Linking Current Year's Sites to Pre-Existing Sites in NJWaTr ...............................................12

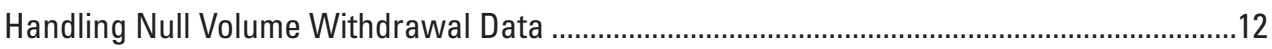

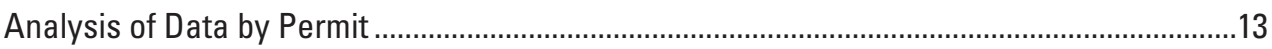

Comparing Current Year's Data to Permit Allocation Limits (Annual and Monthly).................13

Comparing the Current Year's Data to Historical Data ............................................................14

Incorporating Updates to the Historical Dataset ...............................................................14

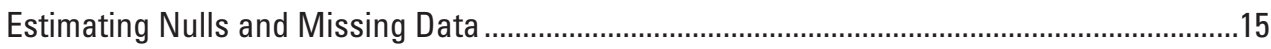

Aquifer Storage and Recovery (ASR) and Surface-Water Returns Data..............................15

Wastewater Discharge Data ........................................................................................... 19

Final Processing of All Quality Assured Data, Including New Sites ......................................20

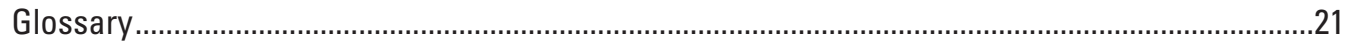

References Cited...............................................................................................................22

Appendix 1 Selected Publications that Include Data from New Jersey Water Transfer

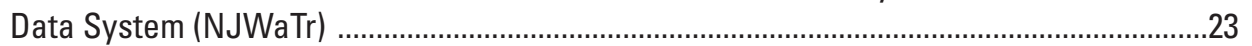

\section{Figures}

1. Schematic diagram showing a flow chart summarizing the quality assurance/ quality control procedure for withdrawal data received from the New Jersey Department of Environmental Protection Bureau of Water Allocation...

2. Screen shot showing example list of files received from the New Jersey Department of Environmental Protection Bureau of Water Allocation ...............................

3. Example table showing format and appearance of the raw NJEMS data file ...................6

4. The form used to run the AllocPreProcessor procedure that generates the SiteGroup Percent table ................................................................................................

5. Schematic diagram showing the basics of allocation permitting and depicting how groups are made up of sites....................................................................................

6. Schematic diagram showing an example of the contents of a permit and how its members, made up of sites and groups, relate to the original permit..........................8

7. Schematic diagram showing an example of the contents of a permit and its members and how the allocation processor works to calculate the percent that each site contributes to the group's overall allocation limit(s) or its site percent ............9

8. Schematic diagram showing example results from the full allocation process, as run on 2006 data...

9. Screen shot showing an example of the SiteGroupPercent table ...................................11 
10. Screen shot showing an example of a group total that differs from the site total ..........11

11. Example table with group and site totals that are not equal, decisions made about keeping the sites' monthly records or the group's monthly records, and current and historical rationales for decisions

12. Example of raw data from the file WATER STORED UNITS MI 01012003 TO MMDDYYYY.csv as received in the electronic dataset delivery from the Bureau of Water Allocation.

13. Example of the "from" and "to" NJWaTr SiteNames for the conveyance of a stored water transfer

14. Example of raw data from the file WATER RECOVERED ASR UNIT MI 01012003 TO MMDDYYYY.csv as received in the electronic dataset delivery from the Bureau of Water Allocation

15. Example of the "from" and "to" NJWaTr SiteNames for the conveyance of a recovered water transfer

16. Example of raw data from the file WATER RETURNED UNITS MI 01012003 TO MMDDYYYY.csv as received in the electronic dataset delivery from the Bureau of Water Allocation.

17. Example of the "from" and "to" NJWaTr SiteNames for the conveyance of a surface-water return transfer

\section{Tables}

1. Examples of changes to the annual withdrawal totals resulting from the Quality Assurance/Quality Control effort

2. Enumerated Quality Assurance/Quality Control Procedure Steps for all water-use data

3. Wastewater method code abbreviations, descriptions, and ranks, as associated with data received from the New Jersey Pollutant Discharge Elimination System 


\section{Conversion Factors}

U.S. customary units to International System of Units

\begin{tabular}{|c|c|c|}
\hline Multiply & By & To obtain \\
\hline gallon (gal) & 3.785 & liter $(\mathrm{L})$ \\
\hline gallon (gal) & 0.003785 & cubic meter $\left(\mathrm{m}^{3}\right)$ \\
\hline gallon (gal) & 3.785 & cubic decimeter $\left(\mathrm{dm}^{3}\right)$ \\
\hline million gallons (Mgal) & 3,785 & cubic meter $\left(\mathrm{m}^{3}\right)$ \\
\hline \multicolumn{3}{|c|}{ Flow rate } \\
\hline gallon per minute (gal/min) & 0.06309 & liter per second $(\mathrm{L} / \mathrm{s})$ \\
\hline gallon per day (gal/d) & 0.003785 & cubic meter per day $\left(\mathrm{m}^{3} / \mathrm{d}\right)$ \\
\hline $\begin{array}{l}\text { gallon per day per square mile }([\mathrm{gal} / \mathrm{d}] / \\
\left.\mathrm{mi}^{2}\right)\end{array}$ & 0.001461 & $\begin{array}{l}\text { cubic meter per day per square kilometer } \\
\left.\qquad\left(\left[\mathrm{m}^{3} / \mathrm{d}\right)\right] / \mathrm{km}^{2}\right)\end{array}$ \\
\hline $\begin{array}{l}\text { million gallons per day per square mile } \\
\qquad\left([\mathrm{Mgal} / \mathrm{d}] / \mathrm{mi}^{2}\right)\end{array}$ & 1,461 & $\begin{array}{l}\text { cubic meter per day per square kilometer } \\
\qquad\left(\left[\mathrm{m}^{3} / \mathrm{d}\right] / \mathrm{km}^{2}\right)\end{array}$ \\
\hline \multicolumn{3}{|c|}{ Volume } \\
\hline liter $(\mathrm{L})$ & 0.2642 & gallon (gal) \\
\hline cubic meter $\left(\mathrm{m}^{3}\right)$ & 264.2 & gallon (gal) \\
\hline cubic decimeter $\left(\mathrm{dm}^{3}\right)$ & 0.2642 & gallon (gal) \\
\hline cubic meter $\left(\mathrm{m}^{3}\right)$ & 0.0002642 & million gallons (Mgal) \\
\hline \multicolumn{3}{|c|}{ Flow rate } \\
\hline liter per second $(\mathrm{L} / \mathrm{s})$ & 15.85 & gallon per minute (gal/min) \\
\hline cubic meter per day $\left(\mathrm{m}^{3} / \mathrm{d}\right)$ & 264.2 & gallon per day (gal/d) \\
\hline $\begin{array}{l}\text { cubic meter per day per square kilometer } \\
\qquad\left(\left[\mathrm{m}^{3} / \mathrm{d}\right] / \mathrm{km}^{2}\right)\end{array}$ & 684.28 & $\begin{array}{l}\text { gallon per day per square mile } \\
\qquad\left([\mathrm{gal} / \mathrm{d}] / \mathrm{mi}^{2}\right)\end{array}$ \\
\hline cubic meter per second $\left(\mathrm{m}^{3} / \mathrm{s}\right)$ & 22.83 & million gallons per day (Mgal/d) \\
\hline $\begin{array}{l}\text { cubic meter per day per square kilometer } \\
\qquad\left(\left[\mathrm{m}^{3} / \mathrm{d}\right] / \mathrm{km}^{2}\right)\end{array}$ & 0.0006844 & $\begin{array}{l}\text { million gallons per day per square } \\
\text { mile }\left([\mathrm{Mgal} / \mathrm{d}] / \mathrm{mi}^{2}\right)\end{array}$ \\
\hline
\end{tabular}




\section{Abbreviations}

$\begin{array}{ll}\text { ASR } & \text { aquifer storage and recovery } \\ \text { BWA } & \text { Bureau of Water Allocation } \\ \text { DBA } & \text { database administrator } \\ \text { GNIS } & \text { Geographic Names Information System } \\ \text { HUC } & \text { Hydrologic Unit Code } \\ \text { ID(s) } & \text { Identifier(s) } \\ \text { MCD } & \text { Minor Civil Division } \\ \text { NJDEP } & \text { New Jersey Department of Environmental Protection } \\ \text { NJEMS } & \text { New Jersey Environmental Management System } \\ \text { NJGWS } & \text { New Jersey Geological and Water Survey } \\ \text { NJPDES } & \text { New Jersey Pollutant Discharge Elimination System } \\ \text { NJWaTr } & \text { New Jersey Water Transfer Data System } \\ \text { NJWSC } & \text { New Jersey Water Science Center } \\ \text { NWIS } & \text { National Water Information System } \\ \text { PI } & \text { Program Interest } \\ \text { OA/OC } & \text { quality assurance/quality control } \\ \text { SSA } & \text { sewer service area } \\ \text { SW } & \text { surface water } \\ \text { UID(s) } & \text { Unique Identifier(s) } \\ \text { USGS } & \text { U.S. Geological Survey }\end{array}$




\title{
Quality Assurance/Quality Control Procedure for New Jersey's Water-Use Data for the New Jersey Water Transfer Data System (NJWaTr)
}

\author{
By Jennifer L. Shourds
}

\section{Abstract}

This report is an instructional reference document that describes methods developed and used by the U.S. Geological Survey (USGS) New Jersey Water Science Center (NJWSC) to assure the quality and completeness of water-use data as provided by the New Jersey Department of Environmental Protection (NJDEP) Bureau of Water Allocation. These data are owned wholly by the State of New Jersey. The role of the USGS NJWSC is to assure the quality of these data by compiling, reviewing, and checking the datasets before uploading them into the New Jersey Water Transfer Data System (NJWaTr) database on an annual basis. The complete uploaded version of the NJWaTr database serves as the repository for New Jersey's approved and published water-use data. The State of New Jersey maintains a public-facing version of the NJWaTr database (available online at https:/www.nj.gov/dep/ njgs/geodata/dgs 10-3.htm) that contains monthly water-use data at the municipality and 14-digit Hydrologic Unit Code subwatershed level. The protected version of the NJWaTr database that contains monthly site-specific water-use data is available from the NJDEP upon request.

\section{Introduction}

Water-use withdrawals in New Jersey vary as a result of (1) population changes within the State, (2) yearly climate effects (larger withdrawals in dry years than in wet years for most water-use categories), (3) land-use changes over time (for example, residential, commercial, and industrial development), and (4) economic effects. (New Jersey Department of Environmental Protection, 2017). Water-use data are important to the State of New Jersey, but data requests also come from scientists studying and modeling groundwater and surface water, university researchers, non-profit organizations, local governmental agencies, and the public sector.

The regulation and data collection for New Jersey's water resources are overseen by multiple New Jersey Department of Environmental Protection (NJDEP) agencies, including programs for land use, water quality, water supply, and wildlife. Two issues common to these programs are the limited amount of water available to meet competing demands and the lack of available water-use data. Independent collection and storage of water-use data by these agencies make data retrieval and use problematic. Water-resource managers and scientists require a single source of consistent, accurate, relevant, and easily accessible water-use data to plan for current demands and future needs.

In the early 1990s, the USGS established an internal water-use database (specific to the New Jersey Water Science Center [NJWSC]) that contains monthly site-specific withdrawal data from 1918 to the present and has been compiling, checking, and preparing quality-assured water-use data for its own projects since the early 1990s. To help the State of New Jersey meet its water-supply-planning goals and to provide a centralized database to house water-use data, a cooperative project between the NJDEP New Jersey Geological and Water Survey (NJGWS) and the USGS led to the creation of the New Jersey Water Transfer Data System (Tessler, 2003), commonly referred to as NJWaTr or the NJWaTr database. The NJWaTr database was initially populated with 10 years of New Jersey water-use, water-transfer, and related data from 1990 through 1999.

One of the cooperative project's main goals is to annually populate the NJWaTr database with quality-assured, site-specific monthly data. As such, the USGS developed a procedure to assure the quality of the data received from the NJDEP Bureau of Water Allocation (BWA) and has adapted the procedure to meet the needs of the cooperative project throughout the years. This quality assurance/quality control (QA/QC) procedure has evolved over time, and the steps have been automated whenever possible.

Table 1 shows that for 2004 to 2010, the QA/QC procedure was very important in ensuring the quality and accuracy of the data in NJWaTr. The large percentage decreases in total annual withdrawals, original (raw) data compared to qualityassured data, ranging from 91.2 to 99.7 percent, justify the need to correct the raw data received from the State and track changes made to the original data. Large errors generally result from order of magnitude errors as a result of incorrect 
Table 1. Examples of changes to the annual withdrawal totals resulting from the Quality Assurance/Quality Control effort.

[QA/QC, quality assurance and quality control; Mgal/yr, million gallons per year; NJDEP New Jersey Department of Environmental Protection; BWA, Bureau of Water Allocation; NJWaTr, New Jersey Water Transfer Data System]

\begin{tabular}{|c|c|c|c|}
\hline \multirow[b]{2}{*}{ Year } & \multicolumn{2}{|c|}{ Sum of annual withdrawals, in Mgal/yr } & \multirow[b]{2}{*}{$\begin{array}{l}\text { Decrease in sum of annual withdrawal } \\
\text { from original, in percent }\end{array}$} \\
\hline & $\begin{array}{c}\text { Pre QA/OC, original (raw) data from } \\
\text { NJDEP BWA }\end{array}$ & Post QA/OC data, as stored in NJWaTr & \\
\hline 2004 & $376,567,740$ & $1,031,222$ & 99.7 \\
\hline 2005 & $70,416,700$ & $1,062,918$ & 98.5 \\
\hline 2006 & $136,318,122$ & $1,024,497$ & 99.2 \\
\hline 2007 & $131,747,707$ & 946,181 & 99.3 \\
\hline 2008 & $160,190,301$ & 917,739 & 99.4 \\
\hline 2009 & $129,787,103$ & $1,172,169$ & 99.1 \\
\hline 2010 & $8,162,042$ & 716,109 & 91.2 \\
\hline
\end{tabular}

units reported by the purveyor. These types of units errors, as well as other types of errors, are fixed as a result of the QA/ QC procedure.

The initial cooperative work was followed by further refinements to the data model and the development of tools to assist with updating, exporting, checking, and transforming the data into additional outputs serving specific uses. Recent cooperative work has been focused on updating the original database design and supporting applications to accommodate new requirements and meet user needs, and compiling, checking, and preparing new data that are added annually to the NJWaTr database.

Annual updates to the NJWaTr database ensure that current, high-quality, water-use data are readily available to the NJDEP and other water-use data users from a consistent, centralized source. The site-specific, water-use data are accompanied by relevant information pertaining to each site and its resource. The State of New Jersey maintains a public-facing version of the NJWaTr database (available online at https://www.nj.gov/dep/njgs/geodata/dgs10-3.htm) that contains monthly water-use data at the municipality and 14-digit Hydrologic Unit Code subwatershed level. The protected version of the NJWaTr database that contains monthly site-specific water-use data is available from the NJDEP upon request. Appendix 1 lists selected publications that include the quality-assured, water-use data retrieved from the protected version of NJWaTr.

The purpose of this report is to document the QA/QC procedure that the NJWSC uses to compile, check, and prepare water-use data received from the NJDEP BWA for inclusion in NJWaTr. This report is intended for use as a reference document and is intended to be read by those using data from NJWaTr. Although this report describes the QA/QC procedures performed on many different types of data (withdrawal, aquifer storage and recovery (ASR), surface-water returns, and wastewater), the focus is on the withdrawal data because they account for the largest number of data values and have the most accompanying, ancillary information, which allows inconsistencies and errors to be easily identified and corrected.

\section{Quality Assurance/Quality Control Procedure For New Jersey's Water-Use Data}

The QA/QC procedure has been refined over the years and is presented in this report as a series of steps. The steps are described in the following sections by data type: withdrawal data, aquifer-storage and recovery data, surface-water return data, and wastewater discharge data.

NJDEP BWA provides data tables to the USGS as text files that need to be formatted and verified. The raw datasets arrive in a wide format with one row containing one site and 12 withdrawal volume values for the 12 months of the calendar year. These data are generated by the State's New Jersey Environmental Management System (NJEMS) and are sent to an electronic mailing address list twice a year. Withdrawal data also can be found in raw, original, pre-QA/QC form on the State's data miner website at https://www13.state.nj.us/ DataMiner.

\section{Withdrawal Data}

This section describes the procedure used to compile and assure the quality of the withdrawal water-use data as obtained from the NJDEP BWA. The data include surface-water diversions and groundwater withdrawals. Accompanying site information included in the electronic dataset show which sites are designated as groundwater and which sites are designated as surface water.

The diagram in figure 1 and the outline in table 2 show the steps that make up the $\mathrm{QA} / \mathrm{QC}$ procedure for the withdrawal data in an enumerated format to help the reader follow the steps described in the sections below. 


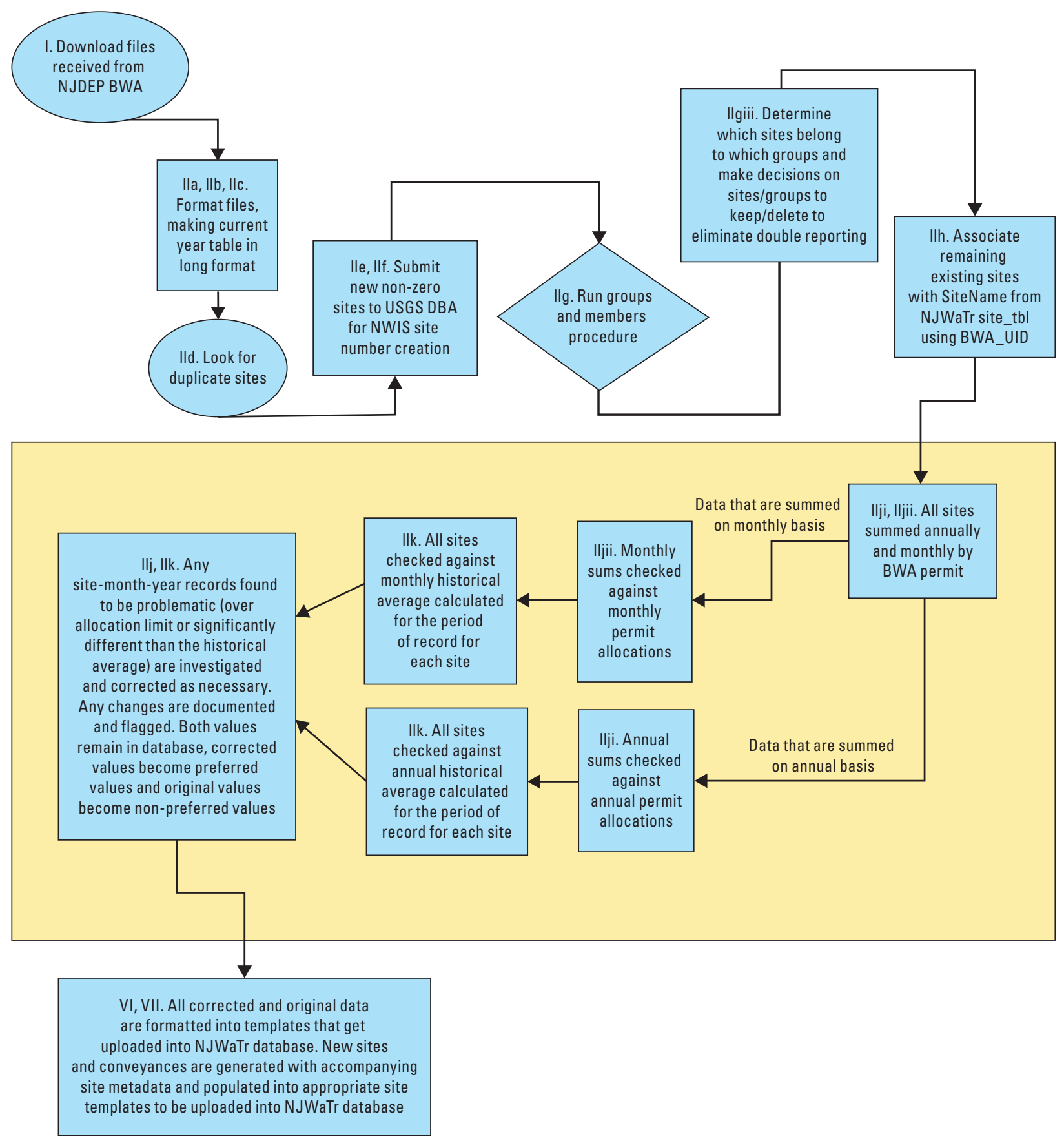

Figure 1. Schematic diagram showing a flow chart summarizing the quality assurance/quality control procedure for withdrawal data received from the New Jersey Department of Environmental Protection Bureau of Water Allocation. Alphanumeric codes in the polygons correspond to process steps in table 2; pale yellow box in center signifies the part of the Quality Assurance/Quality Control procedure where withdrawal volume data checks are executed; step Ili, from table 2, which references handling null withdrawal volume data, is omitted from this diagram for clarity. (NJDEP, New Jersey Department of Environmental Protection; BWA, Bureau of Water Allocation; USGS, U.S. Geological Survey; DBA, Database Administrator; NWIS, National Water Information System; NJWaTr, New Jersey Water Transfer Data System; BWA_UID, Bureau of Water Allocation_Unique Identifier) 
Table 2. Enumerated Quality Assurance/Quality Control Procedure Steps for all water-use data.

[Steps are illustrated in figure 1. QA/QC, quality assurance/quality control; NJDEP, New Jersey Department of Environmental Protection; BWA, Bureau of Water Allocation; USGS, U.S. Geological Survey; NWIS, National Water Information System; NJWaTr, New Jersey Water Transfer Data System; BWA_UID, Bureau of Water Allocation_ Unique Identifier; DBA, Database Administrator]

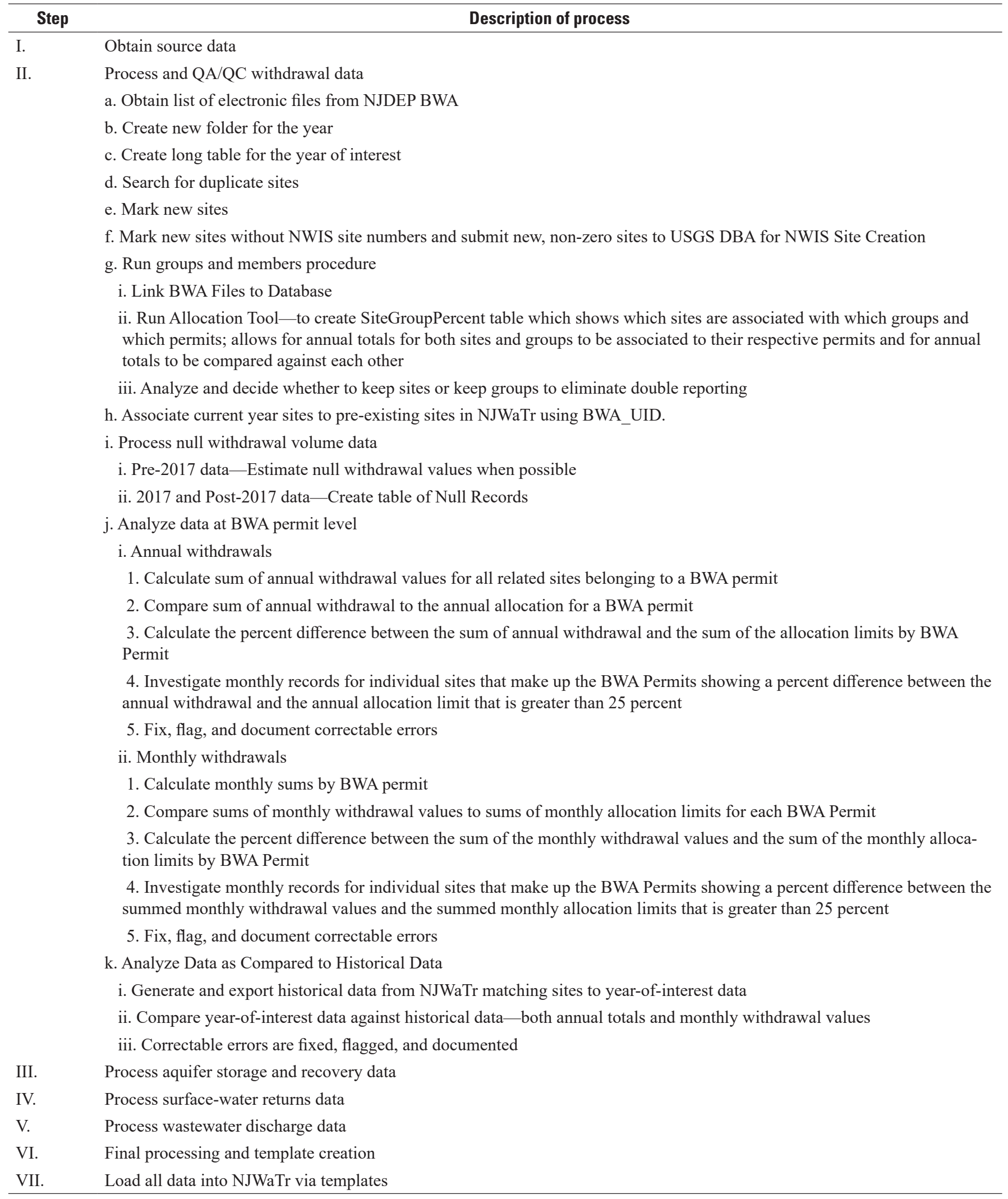




\section{Obtain and Process Source Data}

The data are obtained from the NJDEP BWA twice a year, usually in May and November. The QA/QC procedure is usually based on the November deliverable because the November annual dataset typically contains more datapoints than the May dataset and can be considered a revised, more complete version of the May dataset with fewer null records. The zipped, compressed folder of datafiles includes 17 files, as shown in figure 2 .

To begin the QA/QC process, a new work area folder is set up in the water-use directory with the same configuration as folders from previous years. The work area folder includes the various databases used to format and process the data each year. Each of the 12 databases represents a step in the procedure. Nine of the 12 databases process the withdrawal data (current and historical), one database contains the process for ASR and surface-water returns data, one database contains the process for the wastewater data, and the final database compiles all the data to be stored in one location to generate the NJWaTr final loading templates.
A new data table is created for the new year of data from the electronic file dataset described in figure 2 that represents the year of interest. A link to the most recently received diverted water-data file (in this example, the first file in figure 2 titled "DIVERTED WATER DATA 01012003 to 05202015.csv") is created in the first of the 12 Microsoft Access databases that is used to process and format the data for the year of interest. This DIVERTED WATER DATA file is a comma-separated text file that contains all the monthly withdrawal data from January 2003 to the date of retrieval by the NJDEP BWA. The dataset contained in the DIVERTED WATER DATA file is delivered in a wide format and contains all available data downloaded from the NJDEP BWA database, commonly referred to as NJEMS (fig. 3).

The DIVERTED WATER DATA file, referenced in figures 2 and 3, contains 108,406 rows (sites with multiple years of data from 2003 to 2015 and 2,835 BWA Permits ("PREF_ID_NUM"), which represent 12,391 sites. Because of the current size restrictions that the NJDEP BWA has for NJEMS, this DIVERTED WATER DATA file currently (2020) must be split into three files. From the DIVERTED WATER DATA file, the year of interest table is created, and all the QA/ QC steps are performed upon that dataset. The year of interest

\author{
国 DIVERTED WATER DATA 01012003 TO 05202015 \\ 믈 EFFECTIVE PERMIT SOURCES AND GROUPS BY PI TO 12312013 AND 01012015 \\ 진 EVAPORATIVE WATER CONSUMPTION 01012003 TO 05202015 \\ 몀 PERMITS WITH MONITORED DIVERSION SOURCES TO 12312013 AND 01012015 \\ 문 PHASES LIMITS DATES INITIAL INTERIM FINAL PERMITS 12312013 TO 01012015 \\ 包 PRODUCT WATER CONSUMPTION UNITS MI 01012003 TO 05202015 \\ 国 SUBJECT ITEMS aka SOURCES BY PI 12312013 TO 01012015 \\ 区일 SUBJECT ITEMS WITH LIMITS 12312013 TO 01012015 \\ Xa WATER RECOVERED ASR UNIT MI 01012003 TO 05202015 \\ 젼 WATER RETURNED UNITS MI 01012003 TO 05202015

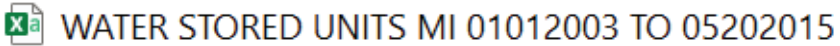 \\ 国 WUGrdToSys units MI 01012003 TO 05202015 \\ 区âl WUINTCONEXPORTED UNITS MI 01012003 TO 05202015 \\ 区a WUINTERCONIMPORTED UNITS MI 01012003 TO 05202015 \\ 区日్ \\ 国 WUTOTEXP UNITS MI 01012003 TO 05202015 \\ 면 WUTOTIMP UNITS MI 01012003 TO 05202015
}

Figure 2. Screen shot showing example list of files received from New Jersey Department of Environmental Protection Bureau of Water Allocation. 
is selected, and a table is created with a long-table format from the wide-table format with identifiers (IDs) ("PREF ID_NUM", "SUBJECT_ITEM_ID", and "SUBJECT_ITEM_ DESIGNATION", which are the second, third, and last columns in the DIVERTED WATER DATA file, respectively, as shown in figure 3). Each month is represented by a column heading, and the volume (in million gallons) is listed below the heading. Each month (January through December) is appended to the table, and total record counts are checked to ensure the long table was generated properly.

\section{New Site Identification Creation and Vetting for Duplicates}

The year of interest table, generated in the first Microsoft Access database, is linked into the subsequent Microsoft Access databases and used to check for duplicate sites and duplicate ID numbers, both of which are rectified, where appropriate. In general, duplicate data are relatively straightforward to rectify. They typically consist of duplicate withdrawal volume values with the same BWA_Unique Identifier (BWA_UID) (shown in fig. 3 as SUBJECT_ITEM_ID) but different BWA Permits (shown in fig. 3 as PREF_ID_NUM). Some duplicate BWA_UIDs exist under different BWA Permits with some missing monthly data, whereas the same site (same BWA_UID under a different BWA Permit) has actual values for those same months. Other cases of duplicate IDs require more investigation. If two withdrawal volume values are different for a specific site-month-year combination, both withdrawal volume values are included as separate records but with two different NJWaTr SiteName IDs (which reflects the different BWA permit within the SiteName). The NJWaTr SiteName is made up of the BWA permit and the SUBJECT_ITEM_DESIGNATION; for example, in figure 3, the NJWaTr SiteName for the site on the first row would become BWA:10000W:4500061135. The various
IDs-BWA Permit (listed in fig. 3 as PREF ID NUM), BWA_UID (listed in fig. 3 as SUBJECT_ITEM_ID), and NJPermit (listed in fig. 3 as SUBJECT_ITEM_DESIGNATION) - are used to compare to existing sites in the USGS National Water Information System (NWIS). Sites that do not have corresponding NWIS site numbers are considered new sites. New sites are listed in a separate table, in addition to any pre-existing sites that do not yet have NWIS numbers (hereafter referred to as "undocumented").

The NWIS site number is a unique identification number for a groundwater or surface-water site that has been created by the NJWSC database administrator (DBA). The link between the State's water-use sites (NJWaTr SiteNames) and the USGS sites (NWIS site number) is important because additional information is contained within the NWIS sitefile that describes the site, making the water-use data contained in NJWaTr more informative and useable for certain situations, such as groundwater flow models. For example, for a groundwater water-use site, NWIS contains information regarding the location and depth of the well and the aquifer in which the well is screened and from which the well is drawing water.

Annual totals of monthly withdrawal values are summed, per site, in order to avoid generating an NWIS site number for sites that have a zero-volume total withdrawal for the year. Oftentimes, new sites with a zero-volume total withdrawal for the year are sites proposed for construction and when constructed will have non-zero annual totals in subsequent years. When this occurs, sites are subsequently created and entered in the year in which there is a non-zero-volume annual withdrawal total. New sites, and any undocumented sites, are submitted to the NJWSC DBA to be entered into the NWIS database, given a new, unique NWIS site number, and tracked as new water-use sites. Typically, 80 to 100 new sites with non-zero-volume annual withdrawal totals are added to the NWIS database in any given year.

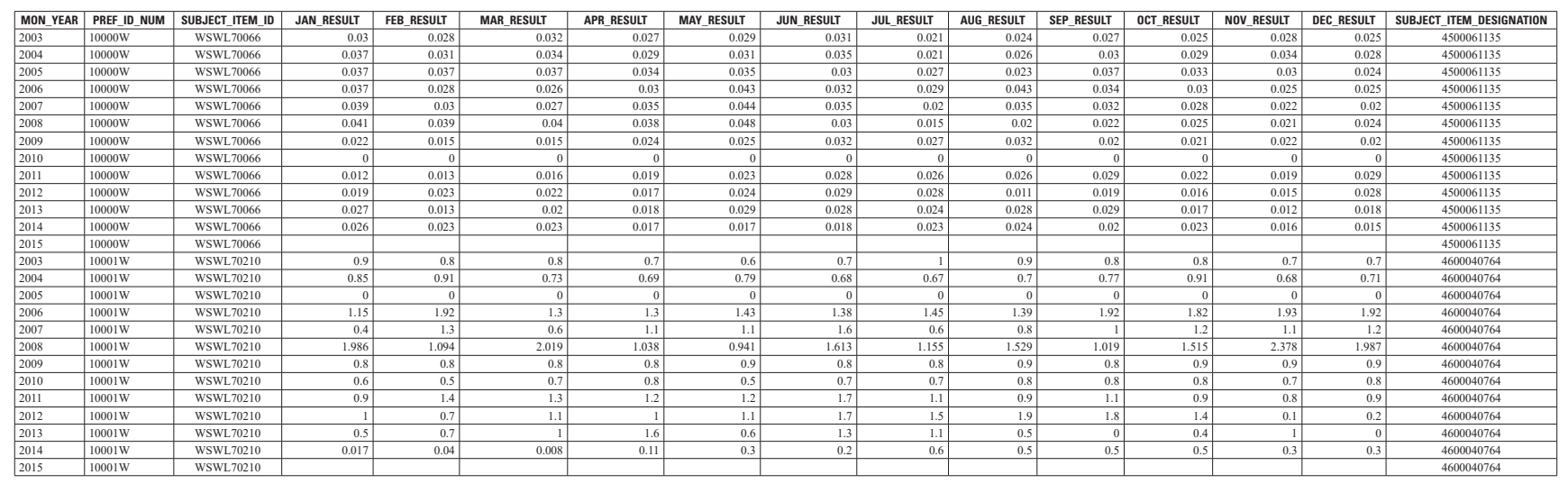

Figure 3. Example table showing format and appearance of the raw NJEMS (New Jersey Environmental Management System) data file. (MON, Monitoring; PREF, Preferred; ID, Identification; NUM, Number) 


\section{Groups and Members Procedure}

The groups and members procedure determines which group(s) each site belongs to. This procedure was set up originally to elucidate the allocation limit (full allocation) per site from an interwoven group of allocation limits where sites are part of multiple groups, sometimes as members of more than one group with differing allocation limits. Two text files from the NJDEP BWA electronic file dataset (EFFECTIVE PERMIT SOURCES AND GROUPS BY PI TO MMDDYYYY and MMDDYYYY.csv and SUBJECT ITEMS WITH LIMITS MMDDYYYY and MMDDYYYY.csv, see fig. 2) are linked into the procedural database titled the AllocPreProcessor (see fig. 4). The AllocPreProcessor database runs the sites and groups procedure that generates a table, SiteGroupPercent, that shows which sites, according to BWA permit, belong to which groups. A BWA permit consists of a group of sites and (sometimes) groups that share the same owner. Owners can possess more than one BWA permit and often require multiple permits over time, as new resources are obtained and utilized.
As shown in figures 5-8, a site can be a member of more than one group, but both the groups and members (sites) that make up the group have the same BWA permit number. Figures 5-8 illustrate the complexity of the allocation permitting process and depict example results from the sites and groups procedure needed to parse out which sites belong to which group(s). A tool in Microsoft Access, which includes the AllocPreProcessor, was developed to elucidate the smallest allocation per site (Mary Chepiga, USGS, written and oral commun., 2016).

Part of the allocation limit per site process generates the SiteGroupPercent table (fig. 9) that lists groups and associated member sites. The SiteGroupPercent table is instrumental in the process of determining which groups or which sites to retain to avoid the double counting; double counting results from double reporting that occurs in the raw data from the electronic dataset. For example, site WSWL960664 in figure 9 is a member of two groups - in this case, group WARG1019538 and group WSWA73890. When this situation is encountered, the steps described below are taken to determine whether to retain the sites' or the group's withdrawal data.

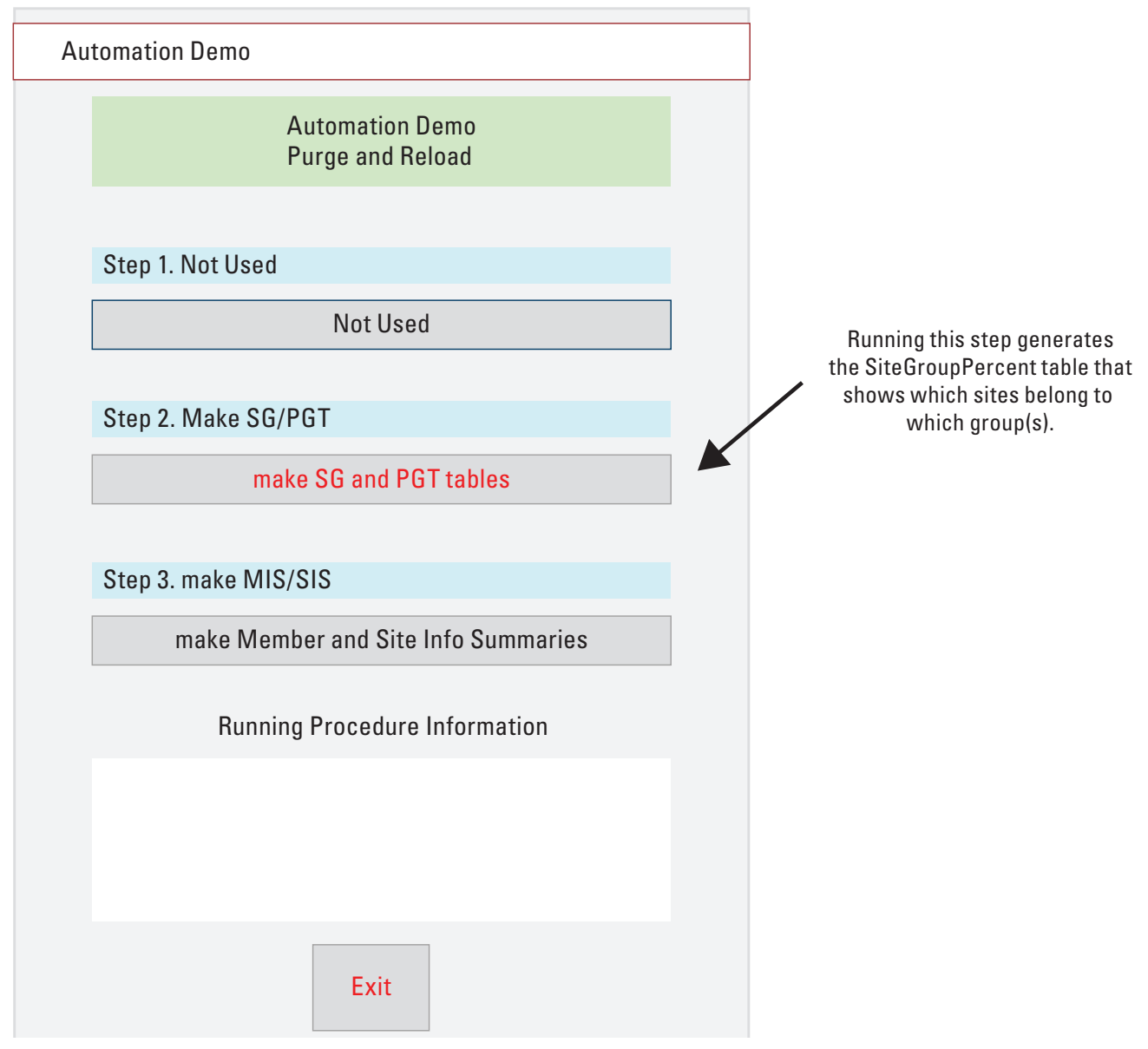

Figure 4. The form used to run the AllocPreProcessor procedure that generates the SiteGroupPercent table. 


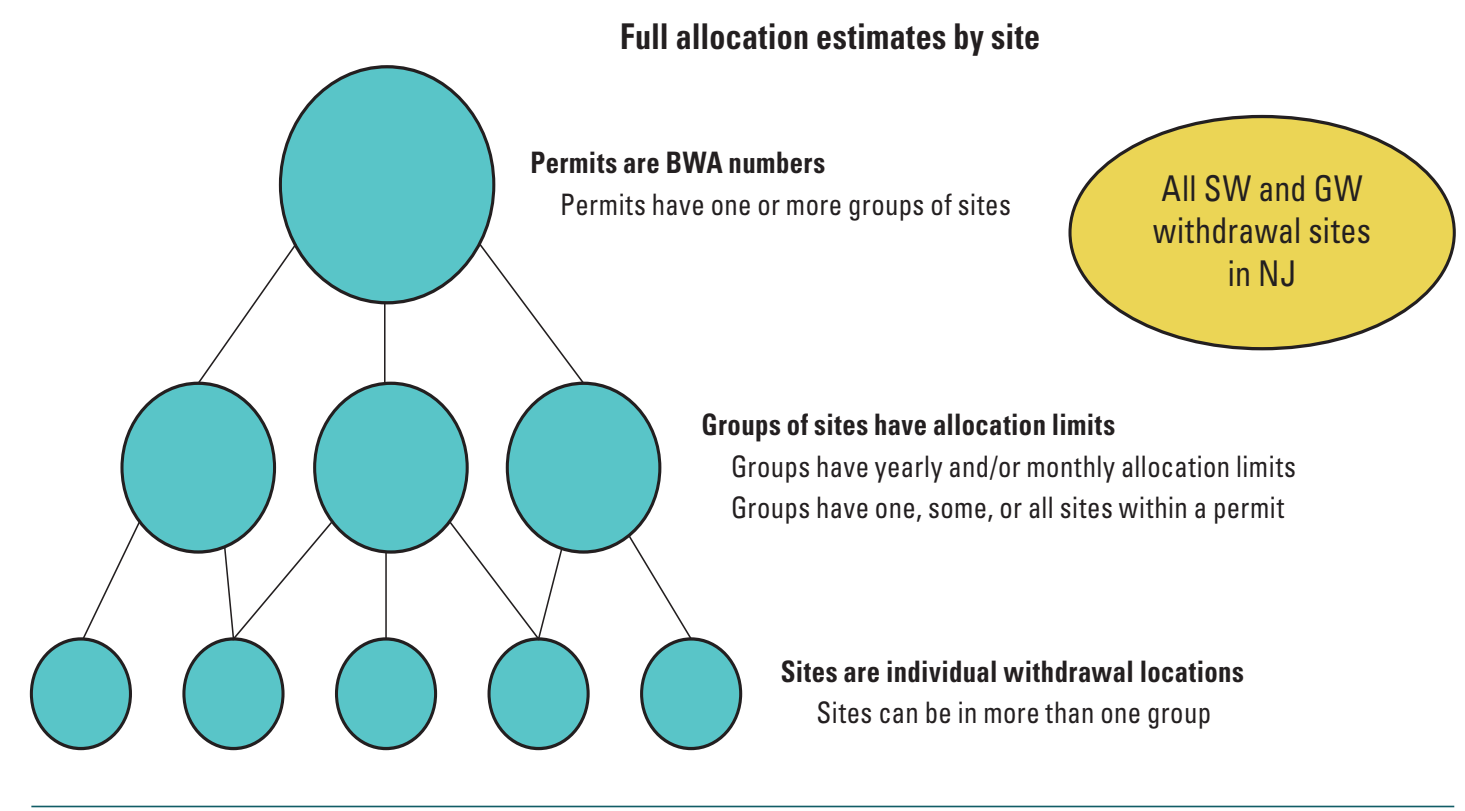

Needed information: $\quad$ 1. Relation of sites to groups 2 . Site percent of groups 3 . Group allocation limit

Figure 5. Schematic diagram showing the basics of allocation permitting and depicting how groups are made up of sites. (BWA, Bureau of Water Allocation; SW, Surface Water; GW, Groundwater; NJ, New Jersey)

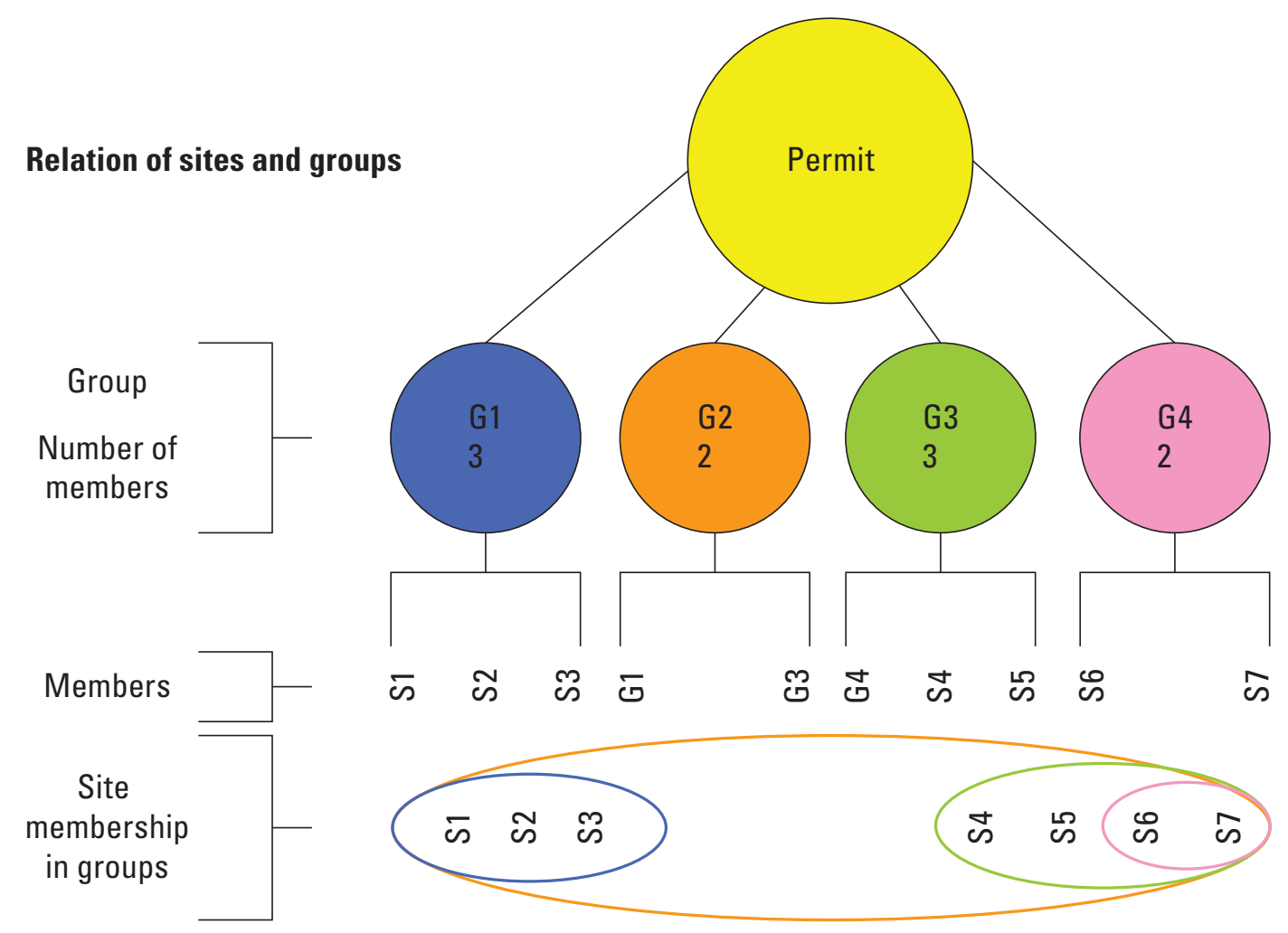

Figure 6. Schematic diagram showing an example of the contents of a permit and how its members, made up of sites and groups, relate to the original permit. (G, Group; S, Site) 
Estimate yearly site allocations

-Identify "smallest" group

- Calculate

- Available allocation

- Number of unallocated sites

- Site percent

Group

Available allocation which equals the allocation limit, in mgy

Number of sites

Site percent
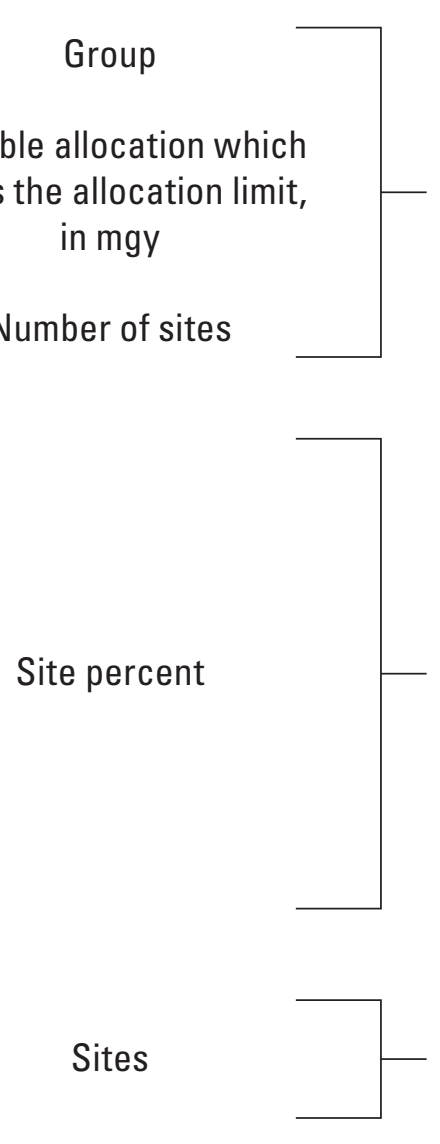

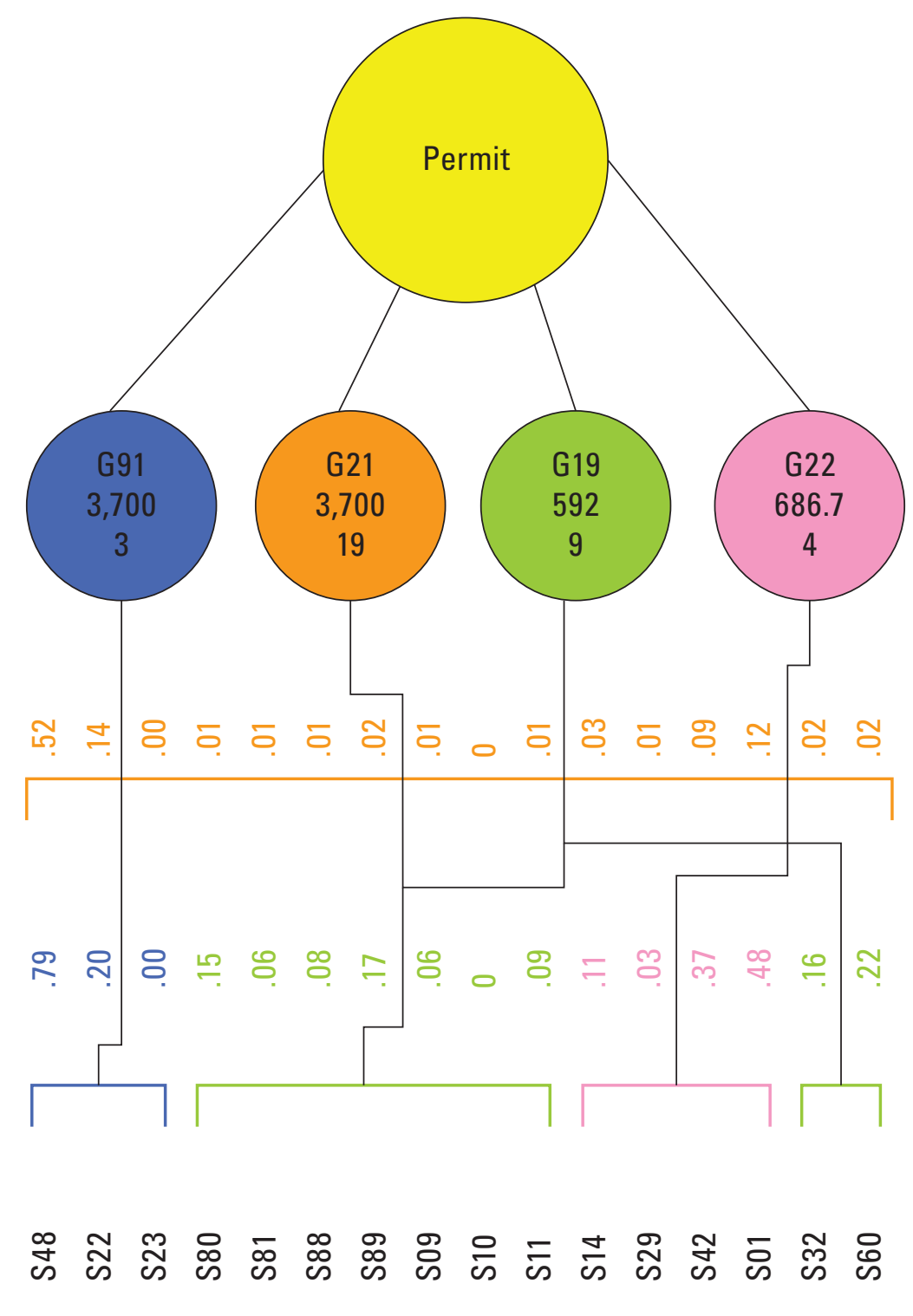

Figure 7. Schematic diagram showing an example of the contents of a permit and its members (made up of sites and groups) and how the allocation processor works to calculate the percent that each site contributes to the group's overall allocation limit(s) or its site percent. (G, Group; S, Site) 
Full allocation estimates by site in 2006

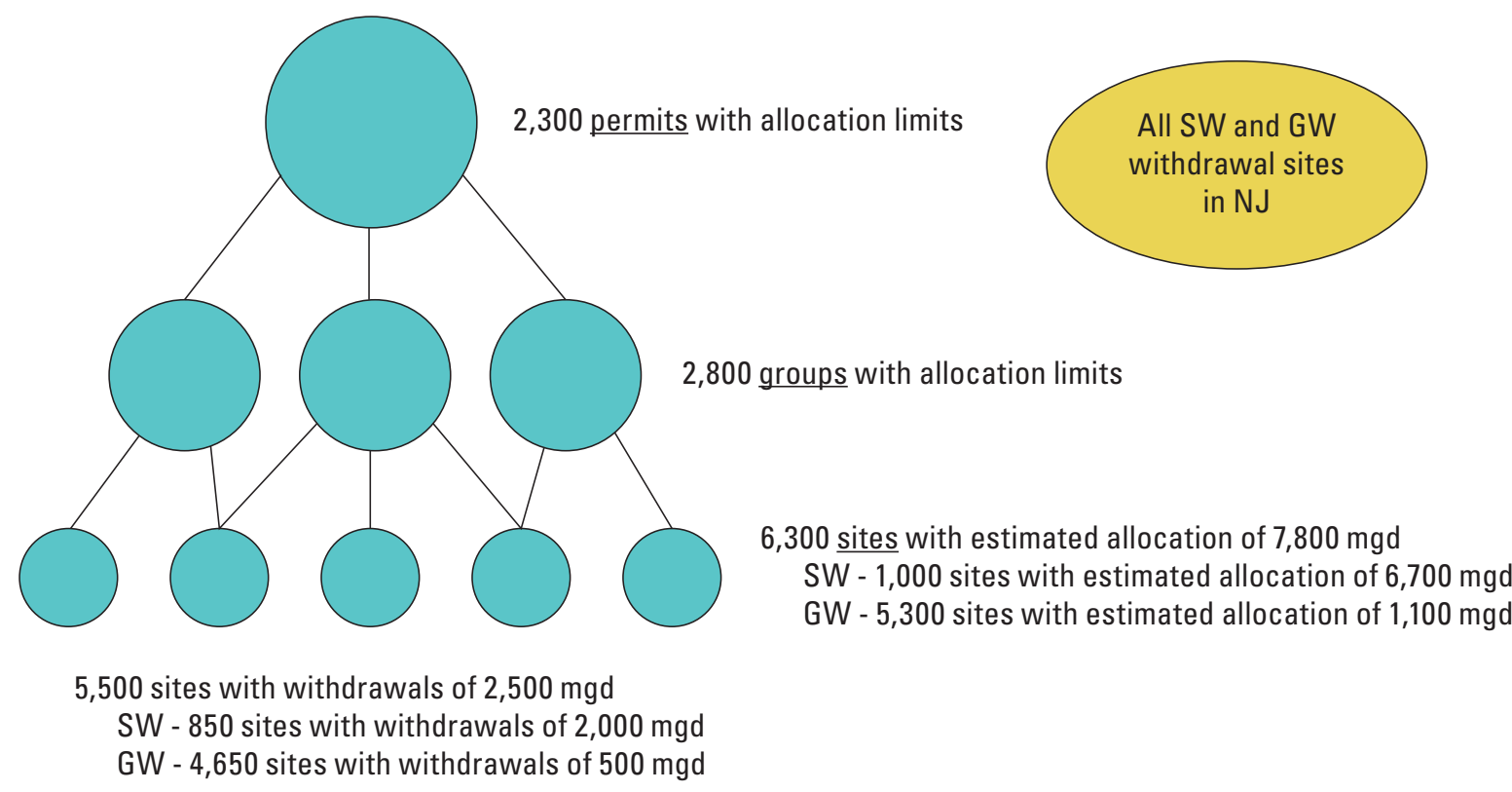

Figure 8. Schematic diagram showing example results from the full allocation process, as run on 2006 data. (SW, Surface Water; GW, Groundwater; NJ, New Jersey; mgd, million gallons per day)

Once the SiteGroupPercent table has been generated, the annual withdrawal value totals are calculated for the groups and the individual sites. The annual withdrawal totals for the individual sites that make up a group are then summed for comparison to the annual group withdrawal total (fig. 10). The summed site total and group total may differ as a result of the way in which the water-use data are reported by the permittee. The permittee may report a group value only, individual withdrawal values for some or all of the sites, or both, depending on reporting requirements. In some situations, the group and site totals do not match, and as a result, a decision must be made as to whether there is more confidence in the group total or the summed site total. If the sum of the individual sites within a group has a non-zero withdrawal value and the group total is null, the individual sites are retained. If the annual total for the group has a non-zero withdrawal value and the sum of the individual sites within that group is null, the group value is retained. In some situations where both the group and the sites making up that group have a non-zero sum total, it is necessary to compare the totals to determine which group, or group of sites, to retain in order to avoid double counting (fig. 10). In order to determine which group, or group of individual sites, is more complete and more accurately represents the actual volumes of withdrawals, the totals are compared. If there are null values within either the group or the site values (for example, a site within the group may have no data for a whole year or may have months within the year with no data [partial year data]), precedence is given to keeping the group. Another evaluation compares the historical decision made for the group and its site members and uses that decision as guidance for the year of interest's data. This method establishes consistency over time. In general, the preference is to keep the individual site data and discard the group data to retain as much sitespecific data as possible. In the example shown in figure 10 , the total withdrawal for all sites equals 2,048.383 million gallons per year, and the total withdrawal for the corresponding group equals $18,435.564$ million gallons per year. In this situation, the sites and their monthly records were retained, and the group and its monthly records were deleted because the site data were complete and contained no null monthly records nor any sites with all null withdrawal values. Though the total withdrawal for the group was larger, that total was deemed not as trustworthy as the withdrawal data for individual sites. In addition, historically, this group and its monthly data have been deleted, and the sites and their monthly records have been retained, during the previous years' QA/QC processing.

Typically, keeping sites has precedence over keeping groups, and historically, the site data have been retained and the group data have been removed roughly 90 percent of the time. This check produces a table (fig. 11), which provides justification and documentation for the decision made for each case. Once decisions have been made, the original dataset is marked with "keep sites" or "keep group," and associated monthly records are deleted, as appropriate. 


\begin{tabular}{|c|c|c|c|}
\hline Permit & ना & Group & Site \\
\hline 10054W & & WARG1019538 & WSWL960664 \\
\hline $10054 W$ & & WSWA73890 & WSWL960664 \\
\hline $10054 W$ & & WARG1019538 & WSWL69266 \\
\hline $10054 W$ & & WSWA73890 & WSWL69266 \\
\hline $10054 W$ & & WARG1019538 & WSWL68952 \\
\hline $10054 W$ & & WSWA73890 & WSWL68952 \\
\hline $10055 W$ & & WARG985573 & WSWL68687 \\
\hline $10055 W$ & & WSWA73886 & WSWL68687 \\
\hline $10055 W$ & & WARG985573 & WSWL202583 \\
\hline $10055 W$ & & WSWA73886 & WSWL202583 \\
\hline $10057 W$ & & WSWA74445 & WSWL70050 \\
\hline 10057W & & WSWA74445 & WSWL65162 \\
\hline $10057 W$ & & WSWA74445 & WSWL64953 \\
\hline 10057W & & WSWA74445 & WSWL64932 \\
\hline
\end{tabular}

Figure 9. Screen shot showing an example of the SiteGroupPercent table. A site can be a member of more than one group; for example, site WSWL960664 (highlighted in yellow) is a member of group WARG1019538 (circled in red) and group WSWA73890 (circled in blue).

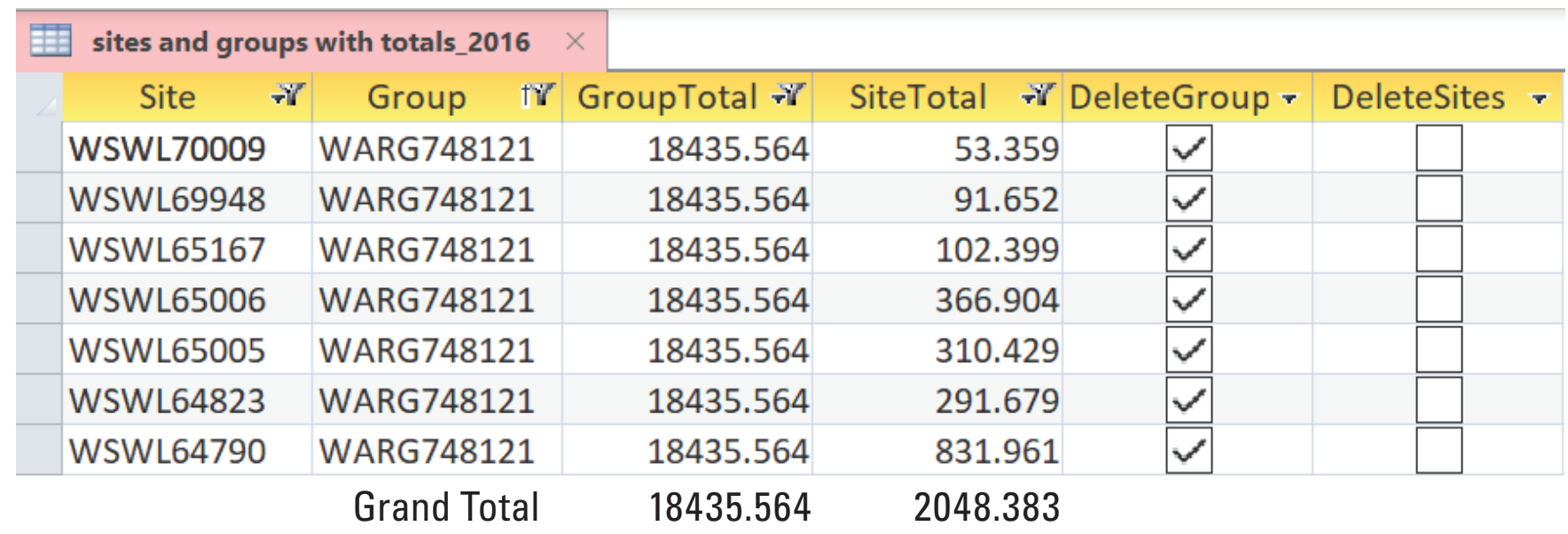

Figure 10. Screen shot showing an example of a group total that differs from the site total. (All withdrawal values are in units of million gallons per year) 


\begin{tabular}{|c|c|c|c|c|c|c|}
\hline Group & BWA & GroupTotal & Sum0fSiteTotal & What to do & Comment & Historical \\
\hline WSWA81635 & $5000 \mathrm{X}$ & 115300.12 & 4434.624 & keep sites & checked nulls, some sites have recent data (2012 and 2015) but historically keep sites & Keep sites \\
\hline WARG81637 & $5000 \mathrm{X}$ & 25975.572 & 1855.399 & keep sites & no nulls in sites & \\
\hline WSWA 81600 & $5014 \mathrm{X}$ & 142130.45 & 2655.246 & keep sites & checked nulls, haven't seen non-zero withdrawals in many $(10+)$ years if ever & Delete group \\
\hline WSWA83808 & $5020 \mathrm{X}$ & 5688826.8 & 48884.7589 & keep sites & checked nulls (lots) but despite recent data (up to 2015, looks estimated) and keeping with historical & Delete group \\
\hline WSWA75771 & $5062 \mathrm{X}$ & 108.3 & 36.1 & keep sites & checked nulls, haven't seen withdrawals in many $(10+)$ years & Delete group \\
\hline WSWA75770 & $5062 \mathrm{X}$ & 572.784 & 0 & keep group & nulls and zero summed sites & \\
\hline WSWA81571 & $5188 \mathrm{X}$ & 2844.355 & 167.315 & keep sites & checked nulls, haven't seen non-zero withdrawals in many $(10+)$ years if ever & Keep sites \\
\hline WSWA75826 & $5206 \mathrm{X}$ & 1721.384 & 430.346 & keep sites & checked nulls, one has recentish data 2013 but other is older than $10+$ years & Keep sites \\
\hline WSWA75827 & $5206 \mathrm{X}$ & 17670.862 & 1606.442 & keep sites & no nulls in sites & \\
\hline WSWA75828 & $5206 \mathrm{X}$ & 276.555 & 92.185 & keep sites & no nulls in sites & \\
\hline WSWA75829 & $5206 \mathrm{X}$ & 8028.639 & 908.667 & keep sites & nulls in sites are actually groups and don't exist in NJWaTr at all & \\
\hline WSWA75825 & $5206 \mathrm{X}$ & 884.342 & 441.913 & keep sites & no nulls in sites & Keep sites \\
\hline WSWA670353 & $5220 \mathrm{X}$ & 8212.1 & 631.65 & keep sites & checked nulls, some have recent-ish data going back to 2013 but could be estimations and going with historically & Keep sites \\
\hline WARG748121 & $5264 \mathrm{X}$ & 18435.564 & 2048.383 & keep sites & checked nulls, haven't seen withdrawals in many $(10+)$ years & Delete group \\
\hline WSWA138268 & $5264 \mathrm{X}$ & 35498.021 & 2730.607 & keep sites & checked nulls, haven't seen withdrawals in many $(10+)$ years & Keep sites \\
\hline WSWA533773 & $5347 \mathrm{X}$ & 2575.304 & 321.913 & keep sites & checked nulls, haven't seen withdrawals in many $(10+)$ years & Keep sites \\
\hline
\end{tabular}

Figure 11. Example table with group and site totals that are not equal, decisions made about keeping the sites' monthly records or the group's monthly records, and current and historical rationales for decisions. (BWA, Bureau of Water Allocation)

\section{Linking Current Year's Sites to Pre-Existing Sites in NJWaTr}

Once the duplicate sites and (or) groups have been removed, the remaining site-month-withdrawal volume combinations are linked to the corresponding SiteName in NJWaTr using a few techniques. The sites can be linked to their corresponding SiteNames in the site table in NJWaTr by NJEMS ID, which can be found in the original electronic dataset file DIVERTED WATER DATA 01012003 to MMDDYYYY.csv, listed in the third column as SUBJECT_ITEM_ID (fig. 3). The NJEMS ID, commonly referred to as BWA_UID, is a concatenation of two columns (SUBJECT ITEM CATEGORY_CODE and SUBJECT_ITEM_ID) that can be found in the file SUBJECT ITEMS also known as SOURCES BY PI MMDDYYYY TO MMDDYYYY.csv in the original electronic dataset (fig. 2). Sites can also be linked to their correct, corresponding NJWaTr SiteName by using the previous years' datasets and (or) the lookup table available in the USGS NJWSC historical usage database and linking by PI ID, or Program Interest identifier (BWA Permit), and Subject Item Designation (NJPermit), which are in the files SUBJECT ITEMS also known as SOURCES BY PI MMDDYYYY TO MMDDYYYY.csv and DIVERTED WATER DATA 01012003 TO MMDDYYYY.csv (fig. 3).

For new sites, two new site IDs are generated - an NJWaTr SiteName and an NWIS Site Number. The new NJWaTr SiteName is created using the format BWA: PI ID: Subject Item Designation. The Program Interest Identification (PI ID; BWA Permit), also written as PREF_ID_NUM, and the Subject Item Designation (NJPermit) are items found in the file DIVERTED WATER DATA 01012003 TO MMDDYYYY.csv (fig. 3). An example of a the NJWaTr SiteName using the example data found in the first row in the DIVERTED WATER DATA file in figure 3 is BWA:10000W:4500061135. The NWIS Site Number is a unique identifier generated by the USGS NJWSC DBA that incorporates the longitude and latitude for a groundwater site and the downstream order number for a surface-water site and is used for tracking the site in NWIS. These new sites are entered into the NJWaTr database with their accompanying information-NJWaTr SiteName, NWIS Site Number, NJEMS ID, geographical information that describes the site location and resource, and other identifying information.

\section{Handling Null Volume Withdrawal Data}

For withdrawal data before 2017, any site having null withdrawal values for all 12 months in the year of interest was removed from the dataset because it was decided that the null data points served as holders as they were most likely new sites without any withdrawal values to date. The database does not allow for null values to be entered, and a null value is considered to be different from a known value of zero. A new or proposed site that has 11 months with null withdrawal values and 1 month with a zero value is also removed. A site having all zero or some non-zero withdrawal values for any of the 12 months is retained. In the past, a site having null withdrawal values for all months but displaying non-zero or zero withdrawal values in subsequent datasets, as updated electronic datasets are received from the BWA, was added to the dataset, and for any months with null withdrawal values, values were estimated, if appropriate. Starting with the review of the 2017 data, withdrawal values are no longer estimated for sites with null withdrawal values. Owing to the increasing quality and completeness of the raw data received from the BWA in recent years, estimates were deemed redundant and unnecessary and, as a result, will no longer be calculated. Sites with null withdrawal values will be maintained in a site inventory table to discern sites that have been active in the past but currently have no withdrawals. 


\section{Analysis of Data by Permit}

The next two sections of this report, Comparing Current Year's Data to Permit Allocation Limits (Annual and Monthly) and Comparing the Current Year's Data to Historical Data, describe the parts of the QA/QC procedure where each withdrawal site is checked against various factors to identify errors that can be fixed, flagged, and documented, and then the corrected value, as well as the original value, are both uploaded into the final datafile templates, which are loaded into NJWaTr. The withdrawal data for a site are compared to the corresponding permit allocation limits and to the corresponding historical data on an annual and monthly basis. Sites are checked as grouped into their BWA permit(s) and individually on a site-specific basis. Initially, sites are grouped by their BWA permits and reviewed on an annual basis in order to find and correct the more obvious errors. The sites are then examined at finer temporal and spatial scales to identify the less obvious errors. After potential errors are identified, historical data for the site are used to help identify a corrected or "preferred" value for the site. The annual and monthly permit allocation limits can be found in the file SUBJECT ITEMS WITH LIMITS MMDDYYYY TO MMDDYYYY.csv (fig. 2).

\section{Comparing Current Year's Data to Permit Allocation Limits (Annual and Monthly)}

Annual sums are calculated by summing the monthly withdrawal values for each site which are then summed by BWA permit (PI ID). The annual BWA permit (PI ID) sums are compared to the annual allocation limit for the permit. For the 10,000-series BWA permits' allocation limits are smaller; no more than 100,000 gallons per day are permitted to be pumped, and pump capacities are less than 70 gallons per minute (State of New Jersey Department of Environmental Protection, Division of Water Supply and Geoscience, Water Allocations and Registrations https:/www.state.nj.us/dep/watersupply/a_allocat.html and Water Use Registration Application https://www.state.nj.us/dep/watersupply/pdf/dwr-188.pdf, both accessed August 19, 2019). The sums of the 10,000-series BWA permits are compared against an annual limit of 37 million gallons, as 100,000 gallons per day multiplied by 365 days results in a rounded value of 37 million gallons. For BWA permits with multiple limits, for example the 5000X-series (public-supply permits) the maximum annual allocation limits are culled from the file SUBJECT ITEMS WITH LIMITS MMDDYYYY TO MMDDYYYY.csv, and the grouped BWA permit annual sums from the year of interest's dataset are checked against the maximum allowable annual allocation limits.

The percent differences by permit are calculated, and all permits with a percent difference greater than 25 percent of the annual allocation are flagged to be examined. Percent difference is calculated using the equation

$$
\frac{(\text { absValue }(\mid \text { AnnualSumOfAllWithdrawalsInABWAPermit }- \text { AnnualAllocationLimitForABWAPermit } \mid))}{\text { absValue }(\mid \text { AnnualAllocationLimitForABWAPermit } \mid)} \times 100,
$$

where abs stands for absolute.

Each site associated with the flagged permit is examined, beginning with the largest percent differences. Each site's monthly value is checked for potential typographical and units errors, which are usually easily identifiable at the site-scale level. For sites/permits where a needed correction and (or) revision is not easily identifiable, the sites listed on the permit are compared to associated historical data to determine whether a correction is appropriate using historical data as justification.

Errors found during the annual allocation limit sums procedure check are fixed, flagged, and documented. Both withdrawal values, the original value and the corrected value, are loaded into the final database. The original, raw, "errored" value is loaded as "non-preferred," and the "fixed, corrected" value is loaded as final and "preferred." Any overages (excess over the permitted withdrawals) that are not correctable are retained in the final dataset to be loaded into NJWaTr because withdrawals greater than the BWA permit's allocation limit do happen and do not necessarily constitute an error.

Typically, approximately 10 percent of permits have total withdrawal values greater than their annual allocation limit before corrections are made. For example, analysis of the 2016 data identified that 192 out of 2,262 permits, or about 8 percent, had total withdrawal values greater than their annual allocation limits. The permits and sites listed on the permits were examined for possible errors, and where applicable, values were corrected.

After corrections have been made to monthly withdrawal values that were identified from the comparison of annual withdrawal values and annual allocation limits, the sum of monthly withdrawal values for each permit is re-calculated using the new "preferred" monthly withdrawal values, and the same procedure described in detail above is carried out using monthly allocation permit limits instead of annual allocation permit limits. The monthly allocation limits are contained within the SUBJECT ITEMS WITH LIMITS MMDDYYYY TO MMDDYYYY.csv file. For 10,000-series BWA permits, the monthly limit is 3.1 million gallons per month. 
Errors found during the monthly allocation limit sums procedure check are fixed, flagged, and documented. Both withdrawal values, the original value and the corrected value, are loaded into the final database. The original "errored" value is loaded as "non-preferred," and the "fixed, corrected" value is loaded as final and "preferred."

Typically, approximately 1 percent of permit-month withdrawal values are greater than their monthly allocation limits, after the annual allocation limit check but before corrections are made resulting from the monthly allocation limit check. For example, for 2016 data, 166 of 27,144 permit-month combinations had reported monthly withdrawal values that were outside the monthly allocation limits and needed to be examined for possible correction.

Evaluating annual allocation limits before monthly limits are evaluated allows larger issues and errors to be identified and corrected, which minimizes the number of problem records that are found during the monthly allocation limit check.

\section{Comparing the Current Year's Data to Historical Data}

Data for the year of interest are checked against, and compared to, the historical data by BWA permit and by site. The NJWaTr SiteNames, which were linked in a previous step, are taken from the year of interest dataset and used to export a historical dataset from the current version of the main NJWaTr database that contains all the historical data for those SiteNames. The historical data that are exported from the main NJWaTr database are associated with their corresponding BWA (PI ID) permit. Once exported from the main NJWaTr database, these historical data are summed by BWA (PI ID) permit, by year and by month, and the average, maximum, minimum, and standard deviation are computed. These historical statistics are compared to the annual and monthly withdrawal values for the year of interest, which are already summed on a permit basis from previous steps (comparing year of interest data to annual and monthly allocation limits). A percent difference/error is calculated using the sum of the values for sites belonging to a BWA permit for the year of interest and the historical annual average by BWA permit. The absolute value of the overall difference between the value for the year of interest for a BWA permit total and the historical annual average value for a BWA permit also is calculated. A query is set up that looks at any percent difference greater than 99 percent and any overall difference that is greater than 100 million gallons per year. This query occasionally results in a lot of manual checking, so another query extracts all the potential outliers showing the data for the year of interest for all the sites belonging to the permits that vary significantly from their corresponding historical data to further prioritize the list and identify correctable errors. The data for the year of interest's individual sites that are included on each permit are examined to see whether any outliers or typographical errors can be detected, fixed, and documented, as appropriate. Usually, as a result of the previous annual and monthly allocation limits check, the major problems in the dataset have been corrected and, if not corrected, have already been identified as issues that cannot be fixed or altered.

\section{Incorporating Updates to the Historical Dataset}

In a continuing effort to improve the database, updates to historical data are made from the new electronic delivery dataset. This includes any historical data (from 2003 to 1 year before the year of interest) that may have been missing or estimated (applies to data from 2003 to 2016 only). The new, updated dataset from the BWA contains withdrawal values for previously missing data that need to be added to the historical database. The old, estimated data value is maintained in the database but becomes a "non-preferred" value, whereas the new, updated value becomes the "preferred" value. New withdrawal values are considered to be updates to null or zero withdrawal values in the dataset and typically result from updated information submitted by the purveyor.

To incorporate the historical updates, first, all historical data are extracted from NJWaTr from 2003 to the year before the year of interest. For example, when working on the 2016 QA/QC procedure, data from 2003 to 2015 were extracted from the NJWaTr database. Using the method code (one of the codes contained in NJWaTr, which designates the source of each data record) to filter the dataset, only data that were classified as estimates are selected to avoid having to rerun the duplicate site verification step and the sites and groups procedure. A check is run on non-estimated, historical data to ensure that the BWA has not made any updates or changes to these records that are marked as "preferred" in the database. These records (site-month-year combination) that already exist in the database as estimates are compared to the latest electronic files matched up by month and year to determine whether data that were previously null have since been replaced by actual values. New, reported withdrawal values are preferred to estimated values and are compiled, formatted, and added to the database. The new, updated withdrawal values are run through the $\mathrm{QA} / \mathrm{QC}$ checking process to determine whether they exceed allocation limits (monthly and annually) or appear as outliers against monthly historical statistics (minimum, average, and maximum) for that site. Monthly percent difference calculations are re-calculated for those updated data, and any necessary corrections are made and documented. Corrections are made by examining a permit's annual (and later monthly) allocation limit volume values and historical use for that site's monthly period of record in the same manner as described previously for the data for the year of interest.

Note that the old, estimated value and the new, real, and uncorrected value are retained as "non-preferred" withdrawal values within the database, and the new, corrected (if applicable) value is promoted as the "preferred" or "primary" value for that site for that particular month and year. The new, 
updated withdrawal values and any corrections are stored in the template in the proper format to be uploaded into the NJWaTr database with the data for the year of interest. An annual data update to the NJWaTr database includes the new, withdrawal values for the year of interest and any updates to the historical data that became available, as well as, if applicable, both of the corresponding, corrected withdrawal values discovered during the $\mathrm{QA} / \mathrm{QC}$ procedure. For the historical updates, the older, estimated values that are replaced by the newer, withdrawal values become "non-preferred" withdrawal values, and the updates become "preferred" withdrawal values, but both are retained in NJWaTr and remain trackable. The original data for the year of interest, if corrected, also remain in the database as non-preferred, and the corrections become the preferred withdrawal values. As a result, all original data and any corrections or updates can be tracked, and any changes to the data over time can be easily retrieved from the NJWaTr database.

\section{Estimating Nulls and Missing Data}

The final step in the QA/QC procedure of the year of interest's withdrawal data is to estimate any nulls or missing data from the electronic dataset using historical data. As previously mentioned, this step of the QA/QC procedure ended with the 2016 data and is included here to describe how data were estimated from 2003 to 2016. Null data are culled from the dataset for the year of interest and matched to the exported historical data, by site and month. The null value is estimated using available, preferred historical data for the month and site. The historical data from 2003 to 1 year before the year of interest include updates, corrections, and inclusions from the previous step and are made up of preferred, withdrawal values and non-estimated, withdrawal values only. This allows each site and month combination to have a historical average value per month composed of as many years of available data as possible, without including any estimates in the resulting calculation. Once the monthly historical average is calculated per site, that value replaces any null values in the dataset for the year of interest, using a monthly, site-specific estimation. The new estimated, withdrawal values are marked "estimated" and included in the formatted dataset that are uploaded into the NJWaTr database. Only gaps of missing data in that year of interest's monthly dataset are estimated. For sites having a whole year of missing monthly records, the site's monthly records are not estimated or included, and the sites are assumed to be either proposed sites with data coming online in the future or sites that are potentially in a non-operational status for that year.

The new dataset with the estimated withdrawal values is again compared to the monthly and annual allocation permit total withdrawal values to verify no overages were introduced with the estimations. An overage might indicate the null withdrawal values should have been entered as zero. Corrections are made by examining a permit's annual (and later monthly) allocation limit values and using that sites' historical monthly period of record data as supporting evidence. Any necessary and appropriate corrections are made and documented.

\section{Aquifer Storage and Recovery (ASR) and Surface-Water Returns Data}

Aquifer storage data track the storage of available unused water that is pumped from a useable and accessible source and stored for later use, typically in an aquifer. Potential sources of stored water include groundwater from other aquifers, surface water that has been treated, or treated wastewater. Aquifer recovery data track the removal of this stored water from the aquifer for use at a later date (New Jersey Department of Environmental Protection, 2017). Surface-water return data track water taken from surficial sources, utilized by humans (including industrial, agricultural, and other uses), and then returned to the surface-water system (U.S. Geological Survey, 2013).

Data for aquifer storage and recovery and surface-water returns are obtained from three text files in the electronic data delivery received from NJDEP BWA (fig. 2). Aquifer storage data are acquired from a file titled WATER STORED UNITS MI 01012003 TO MMDDYYYY.csv. Aquifer recovery data are acquired from a file titled WATER RECOVERED ASR UNIT MI 01012003 TO MMDDYYYY.csv (fig. 2). Surfacewater returns data are acquired from a file titled WATER RETURNED UNITS MI 01012003 to MMDDYYYY.csv (fig. 2). The only difference to the file nomenclature over time is that the date at the end of the file name will change as subsequent years are added to the dataset.

Though different in context and meaning, these three types of data are handled similarly. The monthly data for the year of interest are retrieved and transformed from a widetable format (January through December) into a long-table format of monthly data by site and corresponding permit (as for the withdrawal data, described earlier). The data are stored as monthly values, and each site must be associated with its corresponding transfer conveyance parts. A conveyance is the process of transferring water from one place to another and has a "from" side (source) and a "to" side (destination). For example, a transfer may be from a groundwater well or a surface water site to an aquifer for storage, and then from the aquifer to the user. To process these data, the associations must be made between the "from" and "to" sides to link the volume of stored water to its source and its destination.

For aquifer storage and recovery sites, the conveyance sides "from" and "to," which become the From and To SiteNames in NJWaTr, are made up of either the Drinking Water Service Area permit number that is assigned to that particular ASR site or the original site identifier information contained in either the file WATER STORED UNITS MI 01012003 TO MMDDYYYY.csv or the file WATER RECOVERED ASR UNIT MI 01012003 TO MMDDYYYY.csv, with “_ASR” appended to the end. The "from" and "to" sides of the 
conveyance, and the corresponding From and To SiteNames, switch depending on whether the data are storage transfers or recovery transfers.

Storage transfers are associated with their conveyance sides - the "from" side of the conveyance, titled the FromSite SiteName in NJWaTr, becomes "ASR_storage," and the "to" side of the conveyance, titled the ToSite SiteName in NJWaTr, is created by using the associated SiteName (garnered from site identifier information contained in the file entitled WATER STORED UNITS MI 01012003 TO MMDDYYYY.csv) and attaching "_ASR" to the end. The example in figure 12 shows the file titled WATER STORED UNITS MI 01012003 TO
MMDDYYYY.csv in its raw, wide format as delivered in the original electronic file dataset (fig. 2). The PREF_ID_NUM and the SUBJECT ITEM DESIGNATION fields are used to create the ToSite Sitename with "ASR" appended to the end (fig.12, enlarged insets). The example in figure 13 shows the resulting From and To SiteNames that become associated with the storage transfer conveyance. These From and To SiteNames are associated with their corresponding aquifer storage monthly transfer volumes and are uploaded as such into the NJWaTr database.

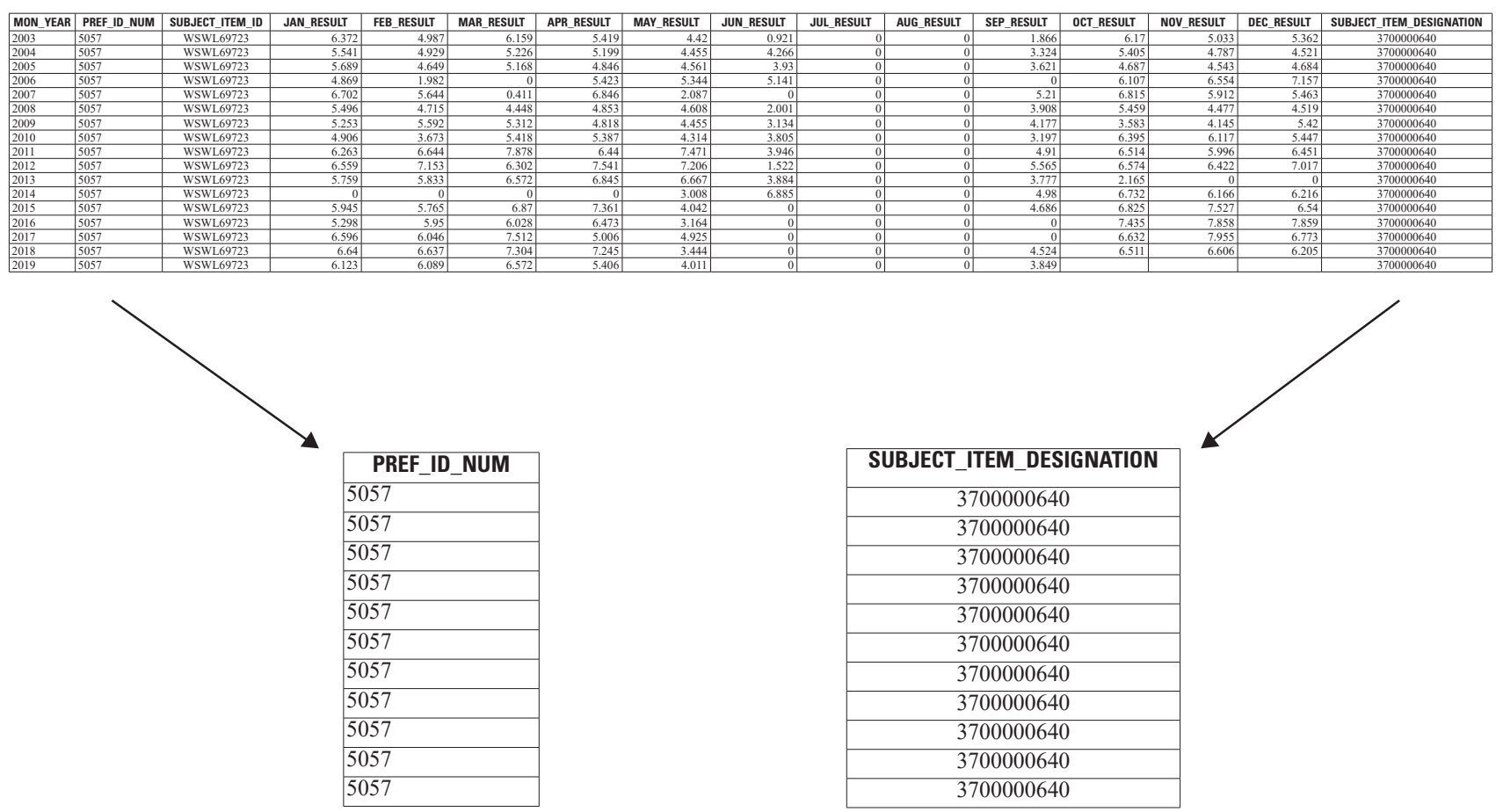

Figure 12. Example of raw data from the file WATER STORED UNITS MI 01012003 TO MMDDYYYY.csv as received in the electronic dataset delivery from the Bureau of Water Allocation. Insets show enlarged columns PREF_ID_NUM (BWA Permit) and SUBJECT_ITEM_DESIGNATION (NJPermit), which make up the "to" side (To SiteName) of the conveyance for stored water transfers. (BWA, Bureau of Water Allocation; MON, Monitoring; PREF, Preferred)

\begin{tabular}{|c|c|}
\hline SiteName_From & SiteName_To \\
\hline ASR_storage & BWA:5057:3700000640_ASR \\
\hline
\end{tabular}

Figure 13. Example of the "from" and "to" NJWaTr SiteNames for the conveyance of a stored water transfer. The "to" side of the conveyance SiteName is derived from the fields provided in the raw data from the file WATER STORED UNITS MI 01012003 TO MMDDYYYY. csv received in the electronic dataset delivery from the BWA. (BWA, Bureau of Water Allocation; ASR, Aquifer Storage and Recovery) 
Recovered water transfers are associated with their transfer conveyance sides. The "from" side of the conveyance, titled FromSite SiteName in NJWaTr, is created by using the associated SiteName (garnered from site identifier information contained in the file WATER RECOVERED ASR UNIT MI 01012003 TO MMDDYYYY.csv) and attaching "ASR" to the end. The "to" side of the conveyance, titled ToSite SiteName in NJWaTr, becomes the associated Drinking Water Service Area, to which that stored water is delivered and used. If the Drinking Water Service Area is unknown, the ToSite SiteName becomes "ASR recovered" as a holder until more information becomes available. The example in figure 14 shows the file WATER RECOVERED ASR UNIT MI 01012003 TO MMDDYYYY.csv in its raw, wide format as delivered in the original electronic file dataset (fig. 2). The PREF ID NUM and the SUBJECT ITEM DESIGNATION fields are used to create the FromSite Sitename with "ASR" appended to the end (fig.14, enlarged insets). The example in figure 15 shows the resulting From and To SiteNames that become associated with the recovered water transfer conveyance. These From and To SiteNames are associated with their corresponding aquifer recovered water monthly transfer volumes and are uploaded as such into the NJWaTr database.

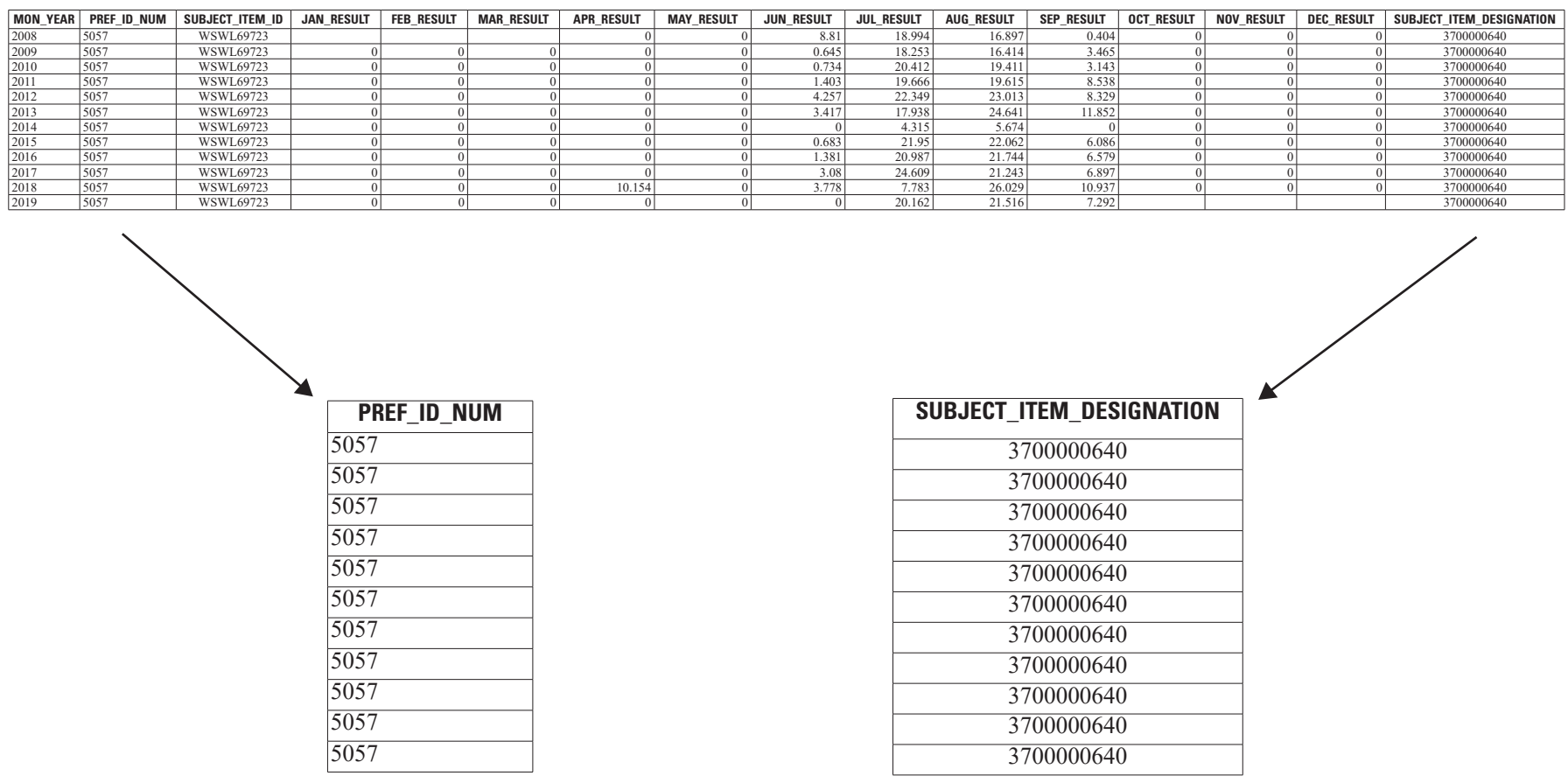

Figure 14. Example of raw data from the file WATER RECOVERED ASR UNIT MI 01012003 TO MMDDYYYY.csv as received in the electronic dataset delivery from the Bureau of Water Allocation. Insets show enlarged columns PREF_ID_NUM (BWA Permit) and SUBJECT_ITEM_DESIGNATION (NJPermit) that make up the "from" side (From SiteName) of the conveyance for recovered water transfers. (BWA, Bureau of Water Allocation; NJ, New Jersey; MON, Monitoring; PREF, Preferred)

\begin{tabular}{|c|c|}
\hline SiteName_From & SiteName_To \\
\hline BWA:5057:3700000640_ASR & DW Service Area 0xxx001 \\
\hline
\end{tabular}

Figure 15. Example of the "from" and "to" NJWaTr SiteNames for the conveyance of a recovered water transfer. The from side of the conveyance SiteName is derived from the fields provided in the raw data from the file WATER RECOVERED ASR UNIT MI 01012003 TO MMDDYYYY.csv received in the electronic dataset delivery from the Bureau of Water Allocation. (BWA, Bureau of Water Allocation; ASR, Aquifer Storage and Recovery; DW, Drinking Water) 
Note that the From SiteName of the recovered water transfer is the same as the To SiteName from the stored water transfer conveyance (the source of the recovered water is the repository of the stored water), and the To SiteName of the recovered water transfer becomes the distribution to its Drinking Water Service Area. Once the aquifer storage and recovery transfers are associated with their corresponding From and To SiteNames and their monthly transfer data for the year of interest, these data can be checked. When complete, the storage and recovery data can be matched against each other on a monthly or yearly basis to track net amounts.

Surface water that is returned to its source is associated with its transfer conveyance sides; the "from" side of the conveyance, titled the FromSite SiteName in NJWaTr, becomes the corresponding BWA Use Area that is associated with its SiteName (garnered from site identifier information contained in the file WATER RETURNED UNITS MI 01012003 TO MMDDYYYY.csv), and the "to" side of the conveyance, titled the ToSite SiteName in NJWaTr, becomes "Return Flow." The example in figure 16 shows the file WATER RETURNED UNITS MI 01012003 TO MMDDYYYY.csv in its raw, wide format as delivered in the original electronic file dataset (fig. 2). The PREF_ID_NUM and the SUBJECT_ITEM_DESIGNATION fields are used to create the FromSite SiteName with "BWA Use Area" appended to the beginning (fig.16, enlarged insets). The example in figure 17 shows the resulting From and To SiteNames that become associated with the surface-water returns transfer conveyance.

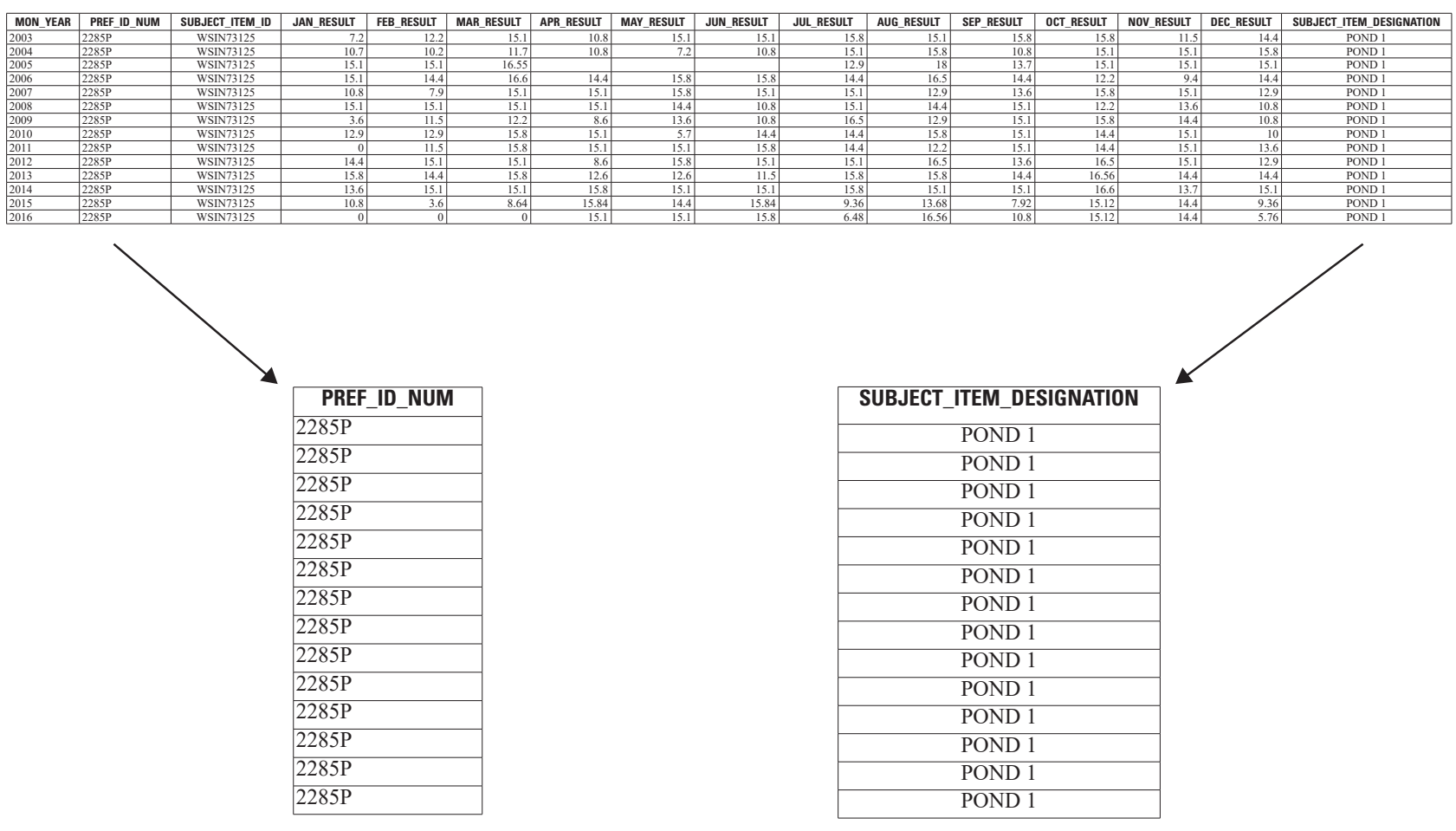

Figure 16. Example of raw data from the file WATER RETURNED UNITS MI 01012003 TO MMDDYYYY.csv as received in the electronic dataset delivery from the Bureau of Water Allocation. Insets show enlarged columns entitled PREF_ID_NUM (BWA Permit) and SUBJECT_ITEM_DESIGNATION (NJPermit) that make up the "from" side (From SiteName) of the conveyance for surface-water return transfers. (BWA, Bureau of Water Allocation; NJ, New Jersey; MON, Monitoring; PREF, preferred)

\begin{tabular}{|c|c|}
\hline SiteName_From & SiteName_To \\
\hline BWA Use Area:2285P:POND 1 & Return Flow \\
\hline
\end{tabular}

Figure 17. Example of the "from" and "to" NJWaTr SiteNames for the conveyance of a surface-water return transfer. The "from" side of the conveyance SiteName is derived from the fields provided in the raw data from the file WATER RETURNED UNITS MI 01012003 TO MMDDYYYY. csv received in electronic dataset delivery from the Bureau of Water Allocation. (BWA, Bureau of Water Allocation) 
The ASR and surface-water returns monthly data records are checked and quality assured as described below. The aquifer storage and recovery data are matched to each other using their corresponding From and To SiteNames and checked against each other. For the ASR data, a month within the year is compared to all other months within that year for those matched storages and recoveries, and the monthly records are compared to previous years' ASR data by site, to elicit any units issues or gross typographical errors. For the surfacewater returns data, a month within the year is compared to all other months within that year, and all months are compared to previous years' surface-water returns data, by site, to elicit any units issues or gross typographical errors. For example, the surface-water return value for March 2015 is compared to all the other surface-water return values for the rest of the months in 2015 and any other monthly value for that site provided in previous years' datasets. Corrections and (or) updates are made, where appropriate, and documented with the proper QA/QC flags.

\section{Wastewater Discharge Data}

The wastewater discharge data, which come from the New Jersey Pollutant Discharge Elimination System (NJPDES), contain multiple measurements for each site for any given month. Each of these measurements is assigned a method code in the original dataset received from NJPDES. These method codes describe the different types of measurements made and are used to evaluate the data. A list of the possible method codes accompanying the wastewater data is show in table 3 . The large amount of wastewater data must be reduced and ranked such that priority can be assigned to the best, most accurate method available in the dataset for that site/month combination. The value for the method that has the highest rank for each site/month combination is the one retained and subsequently loaded into the NJWaTr database. Possible measurement methods, their codes and descriptions, and the ranking list, which prioritizes the different measurement methods, are shown in table 3.

The wastewater data from NJDPES have units different from those stored in NJWaTr, and conversions are done to change units to millions of gallons per month. Some of the discharge volume values must be deleted because letters, symbols, or other characters are in the volume field.

Once the data are formatted and converted to the correct units, a SiteName is generated from the NJPDES permit number, concatenated with the discharge pipe number or monitoring location, for example, NJPDES:NJ0024716.002A. This SiteName becomes the "to" side of the conveyance, also known as the ToSite in NJWaTr, and the "from" side of the conveyance, also known as the FromSite in NJWaTr, is the NJPDES permit number associated with its corresponding Sewer Service Area (SSA), for example, SSA:NJ0024716.

After associating the sites with their conveyance parts, the wastewater discharge volume values are evaluated to determine whether any monthly discharges for the year of

Table 3. Wastewater method code abbreviations, descriptions, and ranks, as associated with data received from the New Jersey Pollutant Discharge Elimination System.

[N/A, Not Available]

\begin{tabular}{|c|c|c|}
\hline Method abbreviation & Method description & Rank \\
\hline 01MOTO & Monthly total & 1 \\
\hline 01MOAV & Monthly average & 2 \\
\hline 01WKAV & Weekly average & 4 \\
\hline 01QTAV & Quarterly average & 5 \\
\hline 01DAAVMN & Daily average minimum & 8 \\
\hline 12MORLAV & N/A & 9 \\
\hline 01WKAVMX & Weekly average maximum & 10 \\
\hline 01QTTO & N/A & 11 \\
\hline 01RPMX & Maximum & 15 \\
\hline 01YRMX & Yearly maximum & 16 \\
\hline 01QTMX & Quarterly maximum & 17 \\
\hline
\end{tabular}


interest exceed the historical average for each month for that site by greater than 50 percent. If any site-month-year combination is discharging more than 50 percent of historical averages for a month, the site-month-year record will be flagged. The flag becomes part of the record uploaded into NJWaTr as part of the template in both the "Column comment" field and the "QA flag" field. Wastewater data are never changed or corrected once the proper unit conversions are made.

Lastly, the checked and potentially flagged wastewater discharge volume values and their FromSite and ToSite SiteNames are compiled into a template to be loaded in the NJWaTr database. For new wastewater sites, new From Site and To Site SiteNames are generated, and other geographical information that describes the site location, as well as other identifying information, are added to the templates to be uploaded into the NJWaTr database.

\section{Final Processing of All Quality Assured Data, Including New Sites}

Once the data have been checked and processed with appropriate documentation, the various data typeswithdrawal, aquifer storage and recovery, surface-water returns, and wastewater - are loaded into templates that are then uploaded to the main NJWaTr database. These templates include the withdrawal/discharge volume data, as well as all accompanying information for new sites. This accompanying information includes new conveyances (associating the "from" side From SiteName with the "to" side To SiteName), any site aliases, site permits, site-location information, resource information, specialized regional area information, Census Block information, water-use type category, and owner information. The site aliases include SUBJECT_ITEM_DESIGNATIONs (also known as NJPermit) and NWIS Site Numbers. The site permits include BWA permit numbers (also known as PI IDs or PREF_ID_NUMs) or NJPDES permit numbers, as appropriate. Site location information includes longitude and latitude, the 14-digit Hydrologic Unit Code (HUC14), the minor civil division (MCD) code, the Geographic Names Information System (GNIS) code, the county code, and the state code. The site resource information includes whether the site is a surface-water or groundwater site, the aquifer in which the groundwater site is drilled and from which the groundwater site is withdrawing, the confinement status for the groundwater site, whether or not the groundwater site is located in a critical area, and the geologic formation information for that site. Specialized regional area information includes whether the site is in the Highlands or Pinelands Preservation Areas or in either of New Jersey's Critical Areas.

After the various templates have been completed and approved, they are uploaded to the NJWaTr database. The NJWaTr database is considered complete for that year of interest, and this new version of the NJWaTr database becomes the current approved version for water-use data for New Jersey. 


\section{Glossary}

AllocationPreProcessor A part of the Allocation Tool that parses out the different groups to which each site belongs.

BWA Permit (Also known as PI ID and PREF_ NUM_ID) A permit number assigned by the New Jersey Department of Environmental Protection Bureau of Water Allocation, that is given to a site or group of sites that share the same owner. An owner may have more than one BWA permit. A BWA permit can be made up of groundwater or surface-water sites and (or) groups. An example of a public supply BWA permit is 5057 .

BWA_UID (Also known as NJEMS ID and SUBJECT_ITEM_ID) A unique identifier assigned by the New Jersey Department of Environmental Protection Bureau of Water Allocation, that is a concatenation of the 4-letter SUBJECT_ITEM_CATEGORY_CODE and a 5- or 6-digit numerical SUBJECT_ITEM_ID, which can be found in the file SUBJECT ITEMS also known as SOURCES BY PI MMDDYYYY TO MMDDYYYY.csv from the original electronic dataset. An example of a BWA_UID for a well is WSWL960664.

BWA Use Area An area that defines where the withdrawn water is used. For withdrawal sites, it is analogous to the To SiteName in NJWaTr.

From SiteName A site name used in NJWaTr for a water-use site that serves as the source of the conveyance of water transferred from one place to another.

GNIS Code A Geographic Names Information System code given to physical and cultural features across the United States.

HUC14 A 14-digit Hydrologic Unit Code that defines a subwatershed's drainage area boundaries.

MCD Code A minor civil division is a code defined by the U.S. Census Bureau that signifies a town, township, or district.

NJEMS ID (Also known as BWA_UID and SUBJECT_ITEM_ID) Another name for BWA_UID, as used in the NJWaTr database site file. See BWA_UID.

NJPermit (Also known as SUBJECT_ITEM_DESIGNATION) Another name for SUBJECT_ITEM_DESIGNATION, as used in the USGS NJWSC's internal database of water-use sites. See SUBJECT_ITEM_DESIGNATION.
NJWaTr SiteName A site name given to a site, mandatory for inclusion into the NJWaTr database. A SiteName is made up of the BWA permit and the SUBJECT_ITEM DESIGNATION. An example is BWA:10000W:4500061135, where $10000 \mathrm{~W}$ is the BWA permit and 4500061135 is the SUBJECT_ITEM_DESIGNATION.

NWIS Site Number A 15-digit number (representing longitude and latitude) given to a groundwater site or an 8-digit number (representing downstream order number) given to a surface-water site by the USGS NJWSC Database Administrator that indicates entry into the National Water Information System (NWIS). A unique identifier for a site in the USGS NWIS database.

PI ID (Also known as BWA Permit and PREF NUM_ID) Another name for BWA Permit, as used in the electronic dataset received from the New Jersey Department of Environmental Protection Bureau of Water Allocation. See BWA Permit.

PREF_NUM_ID (Also known as BWA Permit and PI ID) Another name for BWA Permit, as used in the electronic dataset received from the New Jersey Department of Environmental Protection Bureau of Water Allocation. See BWA Permit.

SUBJECT_ITEM_CATEGORY CODE A code assigned by the New Jersey Department of Environmental Protection Bureau of Water Allocation, to indicate the category to which the site belongs, for example WSWL is used for a well and WSIN is used for a surface-water intake site. When combined with the SUBJECT_ITEM_ID, it makes up the BWA_UID, also known as NJEMS ID.

SUBJECT_ITEM_DESIGNATION (Also known as NJPermit) The State Well Drilling Permit Number or Surface Water Intake Number/Name, as assigned by the NJDEP BWA and used to identify sites in the electronic dataset received from the New Jersey Department of Environmental Protection Bureau of Water Allocation.

SUBJECT_ITEM_ID (Also known as BWA_UID and NJEMS ID) Another name for BWA_UID, as used in the electronic dataset received from the New Jersey Department of Environmental Protection Bureau of Water Allocation. See BWA_UID.

To SiteName A site name used in NJWaTr for a wateruse site that serves as the destination of the conveyance of water transferred from one place to another. 


\section{References Cited}

New Jersey Department of Environmental Protection, 2017, New Jersey water supply plan 2017-2022: West Trenton, N.J., New Jersey Department of Environmental Protection, 484 p, accessed August 19, 2019, at https://www.nj.gov/dep/ watersupply/wsp.html.

Tessler, S., 2003, Data model and relational database design for the New Jersey Water-Transfer Data System (NJWaTr): U.S. Geological Survey Open File Report 03-197, accessed August 20, 2019, at https://pubs.usgs.gov/of/2003/ ofr03197/.

U.S. Geological Survey (USGS), 2013. The water cycle-Surface runoff: U.S. Geological Survey Water Science School web page, accessed August 21, 2019, at https://www.usgs.gov/special-topic/water-science-school/ science/surface-runoff-and-water-cycle?qt-science_center objects $=0 \# q t-$ science_center_objects. 


\section{Appendix 1 Selected Publications that Include Data from New Jersey Water Transfer Data System (NJWaTr)}

Simulated effects of allocated and projected 2025 withdrawals from the Potomac-Raritan-Magothy aquifer system, Gloucester and Northeastern Salem Counties, New Jersey

U.S. Geological Survey Scientific Investigations Report 2011-5033

Prepared in cooperation with the New Jersey Department of Environmental Protection

By: Emmanuel Charles, John P. Nawyn, Lois M. Voronin, and Alison D. Gordon

https://doi.org/10.3133/sir20115033

https://pubs.er.usgs.gov/publication/sir20115033

Simulated effects of groundwater withdrawals from the Kirkwood-Cohansey aquifer system and Piney Point aquifer, Maurice and Cohansey River Basins, Cumberland County and vicinity, New Jersey

U.S. Geological Survey Scientific Investigations Report 2017-5144

Prepared in cooperation with the New Jersey Department of Environmental Protection

By: Alison D. Gordon and Debra E. Buxton

https://doi.org/10.3133/sir20175144

https://pubs.er.usgs.gov/publication/sir20175144

Estimated use of water in the Delaware River Basin in Delaware, New Jersey, New York, and Pennsylvania, 2010

U.S. Geological Survey Scientific Investigations Report 2015-5142

By: Susan S. Hutson, Kristin S. Linsey, Russell A. Ludlow, Betzaida Reyes, and Jennifer L. Shourds

https://doi.org/10.3133/sir20155142

https://pubs.er.usgs.gov/publication/sir20155142

Simulated effects of projected 2010 withdrawals on ground-water flow and water levels in the New Jersey Coastal Plain-A task of the New Jersey Water Supply Plan, 2006 revision

U.S. Geological Survey Scientific Investigations Report 2007-5134

Prepared in cooperation with the New Jersey Department of Environmental Protection

By: Alison D. Gordon

https://doi.org/10.3133/sir20075134

https://pubs.er.usgs.gov/publication/sir20075134

Hydrogeology of, and Simulation of Ground-Water Flow In, the Pohatcong Valley, Warren County, New Jersey U.S. Geological Survey Scientific Investigations Report 2006-5269

Prepared in cooperation with the U.S. Environmental Protection Agency

By: Glen B. Carleton and Alison D. Gordon

https://doi.org/10.3133/sir20065269

https://pubs.er.usgs.gov/publication/sir20065269

Hydrology of the unconfined Kirkwood-Cohansey aquifer system, Forked River and Cedar, Oyster, Mill, Westecunk, and Tuckerton Creek Basins and adjacent basins in the southern Ocean County area, New Jersey, 1998-99

U.S. Geological Survey Water-Resources Investigations Report 2003-4337

By: Alison D. Gordon

https://doi.org/10.3133/wri034337

https://pubs.er.usgs.gov/publication/wri034337

Simulation of the Ground-water flow system in 1992, and simulated effects of projected ground-water withdrawals in 2020 in the New Jersey Coastal Plain Water-Resources Investigations Report 2003-4000

Prepared in cooperation with the New Jersey Department of Environmental Protection

By: Alison D. Gordon

https://doi.org/10.3133/wri20034000

https://pubs.er.usgs.gov/publication/wri20034000 
Simulation of groundwater flow and movement of the freshwater-saltwater interface in the New Jersey coastal plain U.S. Geological Survey Water-Resources Investigations Report 98-4216

By: Daryll A. Pope and Alison D. Gordon

https://doi.org/10.3133/wri984216

https://pubs.er.usgs.gov/publication/wri984216

Simulation of transient ground-water flow in the valley-fill aquifers of the Upper Rockaway River Basin, Morris County, New Jersey

U.S. Geological Survey Water-Resources Investigations Report 2001-4174

Prepared in cooperation with the New Jersey Department of Environmental Protection

By: Alison D. Gordon

https://doi.org/10.3133/wri20014174

https://pubs.er.usgs.gov/publication/wri20014174

Groundwater flow in the New Jersey Coastal Plain

U.S. Geological Survey Professional Paper 1404- H

By: Mary Martin

https://doi.org/10.3133/pp1404H

https://pubs.er.usgs.gov/publication/pp1404H

Geohydrology and simulation of groundwater flow in the Northern Atlantic Coastal Plain aquifer system

U.S. Geological Survey Professional Paper 1404- K

By: P.P. Leahy and Mary Martin

https://doi.org/10.3133/pp1404K

https://pubs.er.usgs.gov/publication/pp1404K

Groundwater flow in the New Jersey coastal plain

U.S. Geological Survey Open-File Report 87-528

By: Mary Martin

https://doi.org/10.3133/ofr87528

https://pubs.er.usgs.gov/publication/ofr87528

Groundwater-withdrawal and water-level data used to simulate regional flow in the major coastal plain aquifers of New Jersey

U.S. Geological Survey Water-Resources Investigations Report 87-4038

By: O.S. Zapecza, L.M. Voronin, and Mary Martin

https://doi.org/10.3133/wri874038

https://pubs.er.usgs.gov/publication/wri874038

Hydrogeology of, and simulated groundwater flow in, the valley-fill aquifers of the upper Rockaway River basin, Morris County, New Jersey

U.S. Geological Survey Water-Resources Investigations Report 93-4145

By: Alison D. Gordon

https://doi.org/10.3133/wri934145

https://pubs.er.usgs.gov/publication/wri934145

Simulated effects of alternative withdrawal strategies on groundwater flow in the unconfined Kirkwood-Cohansey aquifer system, the Rio Grande water-bearing zone, and the Atlantic City 800-foot sand in the Great Egg Harbor and Mullica River Basins, New Jersey

U.S. Geological Survey Scientific Investigations Report 2012-5187

Prepared in cooperation with the New Jersey Department of Environmental Protection

By: Daryll A. Pope, Glen B. Carleton, Debra E. Buxton, Richard L. Walker, Jennifer L. Shourds, and Pamela A. Reilly https://doi.org/10.3133/sir20125187

https://pubs.er.usgs.gov/publication/sir20125187 
Future water-supply scenarios, Cape May County, New Jersey, 2003-2050

U.S. Geological Survey Scientific Investigations Report 2009-5187

Prepared in cooperation with the New Jersey Department of Environmental Protection

By: Pierre J. Lacombe, Glen B. Carleton, Daryll A. Pope, and Donald E. Rice

https://doi.org/10.3133/sir20095187

https://pubs.er.usgs.gov/publication/sir20095187

Summary of the ground-water-level hydrologic conditions in New Jersey 2006

U.S. Geological Survey Fact Sheet 2007-3049

By: Walter Jones and Daryll Pope

https://doi.org/10.3133/fs20073049

https://pubs.er.usgs.gov/publication/fs20073049

Simulation of proposed increases in groundwater withdrawals on the Atlantic City 800-foot sand, New Jersey coastal plain

U.S. Geological Survey Scientific Investigations Report 2006-5114

By: Daryll A. Pope

https://doi.org/10.3133/sir20065114

https://pubs.er.usgs.gov/publication/sir20065114

Use of a groundwater flow model to delineate contributing areas to the Puchack Well Field, Pennsauken township and vicinity, Camden county, New Jersey

U.S. Geological Survey Scientific Investigations Report 2004-5101

By: Daryll A. Pope and Martha K. Watt

https://doi.org/10.3133/sir20045101

https://pubs.er.usgs.gov/publication/sir20045101

Simulation of groundwater flow in the Potomac-Raritan-Magothy aquifer system, Pennsauken Township and vicinity, New Jersey

U.S. Geological Survey Scientific Investigations Report 2004-5025

By: Daryll A. Pope and Martha K. Watt

https://doi.org/10.3133/sir20045025

https://pubs.er.usgs.gov/publication/sir20045025

Hydrogeology, simulation of regional groundwater flow, and saltwater intrusion, Potomac-Raritan-Magothy Aquifer System, Northern Coastal Plain of New Jersey

New Jersey Geological Survey Geological Survey Report GSR 36

Prepared by the U.S. Geological Survey in cooperation with the New Jersey Department of Environmental Protection and Energy Division of Science and Research Geological Survey

By: Amleto A. Pucci, Jr., Daryll A. Pope, and JoAnn M. Gronberg

https://pubs.er.usgs.gov/publication/70159214

Water-level conditions in the confined aquifers of the New Jersey Coastal Plain, 2008

U.S. Geological Survey Scientific Investigations Report 2013-5232

Prepared in cooperation with the New Jersey Department of Environmental Protection

By: Vincent T. Depaul and Robert Rosman

https://doi.org/10.3133/sir20135232

https://pubs.er.usgs.gov/publication/sir20135232

Water-Level Conditions in Selected Confined Aquifers of the New Jersey and Delaware Coastal Plain, 2003

U.S. Geological Survey Scientific Investigations Report 2008-5145

Prepared in cooperation with the New Jersey Department of Environmental Protection

By: Vincent T. dePaul, Robert Rosman, and Pierre J. Lacombe

https://doi.org/10.3133/sir20085145

https://pubs.er.usgs.gov/publication/sir20085145 
Recovery of Ground-Water Levels from 1988 to 2003 and Analysis of Effects of 2003 and Full-Allocation Withdrawals in Critical Area 2, Southern New Jersey

U.S. Geological Survey Scientific Investigations Report 2008-5142

Prepared in cooperation with the New Jersey Department of Environmental Protection

By: Frederick J. Spitz and Vincent T. dePaul

https://doi.org/10.3133/sir20085142

https://pubs.er.usgs.gov/publication/sir20085142

Simulated groundwater flow paths, travel time, and advective transport of nitrogen in the Kirkwood-Cohansey aquifer system, Barnegat Bay-Little Egg Harbor Watershed, New Jersey

U.S. Geological Survey Scientific Investigations Report 2016-5169

Prepared in cooperation with the Barnegat Bay Partnership

By: Lois M. Voronin and Stephen J. Cauller

https://doi.org/10.3133/sir20165169

https://pubs.er.usgs.gov/publication/sir20165169

Simulated effects of groundwater withdrawals from aquifers in Ocean County and vicinity, New Jersey

U.S. Geological Survey Scientific Investigations Report 2016-5035

Prepared in cooperation with the New Jersey Department of Environmental Protection

By: Stephen J. Cauller, Lois M. Voronin, and Mary M. Chepiga

https://doi.org/10.3133/sir20165035

https://pubs.er.usgs.gov/publication/sir20165035

Hydrogeology and Simulated Effects of Ground-Water Withdrawals, Kirkwood-Cohansey Aquifer System, Upper Maurice River Basin Area, New Jersey

U.S. Geological Survey Scientific Investigations Report 2005-5258

Prepared in Cooperation with the New Jersey Department of Environmental Protection

By: Stephen J. Cauller and Glen B. Carleton

https://doi.org/10.3133/sir20055258

https://pubs.er.usgs.gov/publication/sir20055258

Hydrogeology of, water withdrawal from, and water levels and chloride concentrations in the major Coastal Plain aquifers of Gloucester and Salem Counties, New Jersey

U.S. Geological Survey Water-Resources Investigations Report 98-4136

By: S.J. Cauller, G.B. Carleton, and M.J. Storck

https://doi.org/10.3133/wri984136

https://pubs.er.usgs.gov/publication/wri984136

New Jersey Water Supply Plan 2017-2022

By: State of New Jersey Department of Environmental Protection, 2017, 484 p.

https://www.nj.gov/dep/watersupply/wsp.html 
For additional information contact:

Director, New Jersey Water Science Center U.S. Geological Survey

3450 Princeton Pike, Suite 110

Lawrenceville, NJ 08648

Or visit our website at: https://www.usgs.gov/centers/nj-water

Publishing support provided by the West Trenton Publishing Science Center 
